\title{
Ueber Guillaume de Machauts Voir Dit.
}

\section{Einleitung. Litteratur.}

Mit Guillaume de Machauts Hauptwerk Le livre du voir dit hat sich seit seiner Herausgabe durch P. Paris keine Schrift eingehender beschäftigt. Man glaubte, durch diesen Gelehrten seien alle Schwierigkeiten, die dem Verständnis des Gedichts entgegenstehen, beseitigt. Die Angaben über Litteratur sind daher nicht umfangreich. Was in früherer Zeit über das Buch geschrieben ist, wird durch P. Paris wertlos gemacht. Der Titel dieser einzigen Ausgabe lautet: Le livre du voir-dit de Guillaume de Machaut où sont contées les amours de Messire Guillaume de Machaut et de Peronnelle Dame d'Armentières. Avec les lettres et les réponses, les ballades, lais et rondeaux du dit Guillaume et de la dite Peronnelle. Paris 1875. Die Ausgabe ist nach drei Handschriften der Pariser Nationalbibliothek gemacht, die aus des Dichters Zeit sind und die Nummern 1584, 922 I und 22545 tragen. In unserer Abhandlung sollen sie mit A, B, C bezeichnet werden.

Eine Besprechung der Ausgabe befindet sich in der Revue critique d'histoire et de littérature, 1875 No. 121 , von Thamizey de la Roque herrührend, die sich aufs äufserste anerkennend verhält und die von P. Paris gefundenen Resultate als unwiderlegbar bezeichnet.

Teile des Werkes hat Prosper Tarbé herausgegeben in der Collection des poètes de Champagne, u. zw. 1849 in dem Bande: Les ceuvres de Guillaume de Machaut, wo sich u. a. Auszüge aus 3o Briefen des Voir Dit finden, und 1856 in der Sonderausgabe: Poésies d'Agnès de Navarre-Champagne, Dame de Foix. Paris und Reims. I 856. In diesem Bande sind die Gedichte zusammengestellt, die angeblich von der Dame des Dichters, d.h. wie Tarbé annimmt, von Agnes von Navarra, sind. In der sehr ausführlichen Einleitung wird das Leben dieser Prinzessin behandelt und im Zusammenhang damit auch eingehend le livre du voir-dit.

P. Tarbé nimmt also an, die Heldin des Gedichts sei Agnes von Navarra. Das ist eben die Hauptschwierigkeit für das Verständnis des Werkes, dals der Dichter keine bestimmten Namen angegeben hat, sondern Orts- und Personennamen vermeidet und den Leser die Hauptpersonen nur erraten läIst.

Zeitschr. f. rom. Pbil. XXII. 
Tarbé ist nicht der erste, welcher auf Agnes von Navarra gekommen ist. Er ist im Gegenteil zu seiner Meinung durch zwei Gelehrte aus dem vorigen Jahrhundert gebracht worden und hat deren Ansicht ohne weiteres zur seinigen gemacht. Dafs diese nicht haltbar ist, hat P. Paris in der Einleitung seiner Ausgabe gezeigt. Tarbé nimmt als Abfassungszeit des Gedichts das Jahr 1348 an, während vielmehr, wie P. Paris richtig gezeigt hat, die Jahre 1 363-65 als solche anzusetzen sind. - Der erste der beiden Forscher des vorigen Jahrhunderts, welcher über das Voir Dit spricht, ist der Graf Caylus in den Mémoires de l'académie des inscriptions et belles-lettres, Bd. XX: Premier Mémoire sur Guillaume de Machaut, Poëte et musicien dans le quatorzième siècle. Contenant des recherches sur sa vie, avec une notice de ses principaux ouvrages. Er behandelt das Objekt des Buches ausführlicher mit folgenden Worten: L'histoire, les romans même ne fournissent presque point d'exemples d'un amour né sans avoir vu, par la seule estime du caractère, ou par le goût pour les talens: mais ce qui ajoute encore beaucoup à cette singularité, c'est qu'Agnès de Navarre, la Princesse dont il s'agit ici, veuille absolument que les détails de ses amours, les lettres, ses faiblesses mêmes, soient rendues publiques. Je conviens qu'elle n'est point nommée; mais si tout la désigne encore aujourd'hui, ses parens, ses voyages, son pays, combien toutes ces choses étoient-elles plus frappantes dans le temps qu'elles ont paru? ...

In gleicher Weise wird in dem Essai sur la musique ancienne et moderne par B. de Laborde et l'abbé Roussier, IV vol., behauptet, dafs le Voir Dit die Liebe des Dichters zu der Dame behandle, der das Werk gewidmet sei, und das sei Agnes von Navarra.

Im Gegensatz dazu glaubt P. Paris die Heldin in Peronnelle d'Armentières gefunden zu haben, einc Ansicht, auf die wir gleich zurückkommen werden.

Es hat indes auch nicht an Stimmen gefehlt, die behaupten, das ganze Buch schildere nichts wirklich Geschehenes, sondern alles sei vom Dichter erfunden. Die Berechtigung solcher Zweifel giebt schon Tarbé in der Einleitung zu den Poésies d'Agnès de Navarre zu, wenn er sagt S.XIV: Si par hasard, cet original récit n'était qu'un badinage, ce serait encore le premier roman d'amour dont notre poésie n'aurait pas emprunté le sujet au monde fantastique des épopées guerrières. Quelques doutes sur la sincérité de ce récit viendront peut-être au lecteur. La lecture attentive du Voir-Dit révèle des lacunes, des omissions volontaires. Doch weist er solche Zweifel damit zurück, dafs er fortfährt: Mais de ce que l'auteur n'a pas tout dit, il ne peut s'ensuivre que ce qu'il a dit soit inexact. Machaut proteste lui-même de son respect pour la vérité. Un peu de mystère d'ailleurs, n'embellit-il pas la vie réelle?

Mit Entschiedenheit hat sich Mas Latrie in seiner Vorrede 
zur Prise d'Alexandrie dahin ausgesprochen, dais nichts thatsächlich Geschehenes, kein wirkliches Ereignis aus des Dichters Leben dem im Voir Dit Erzählten zu Grunde liege, obwohl der Dichter dieses ausdrücklich an vielen Stellen behauptet. M. Latrie setzt die Abfassungszeit des Buchs in die Jahre $1_{3} 6_{3} / 6_{4}$ und fährt dann fort: C'est là que se placerait la liaison romanesque dont le livre du Voir-Dit, composé en 1363 à I 364 - M. Paulin Paris l'a savamment prouvé - renfermerait la véridique histoire et les monuments authentiques. L'héroïne de l'aventure est une jeune fille de dix-huit à vingt ans. Le héros? On l'ignore. Et peut-être n'y a-t-il pas à rechercher les noms historiques d'une situation trèsvraisemblablement imaginaire. Mais si l'on voulait y voir absolument Guillaume de Machault, il faudrait se résoudre à parler d'un vieillard, d'un goutteux, d'un homme de 75-77 ans! Ia discussion serait-elle encore possible ou nécessaire? Nous en appelons à un nouvel examen du savant éditeur. Pour nous, il nous est impossible de voir dans cette correspondance d'uniformité de rédaction surprenante et quelque peu monotone autre chose qu'une Nouvelle Héloïse du moyen-âge. Gegen diese Ansicht wendet sich aufs heftigste G. Paris in der Revue historique IV, 215.

P. Paris nimmt, wie erwähnt, als Heldin die Peronnelle d'Armentieres an. $\mathrm{Zu}$ diesem Ergebnis ist er auf folgende Weise gekommen.

Im Voir Dit befindet sich auf S. 266 ein Rondel, das den Namen der Dame enthält. Es lautet:

Dis et sept, cinc, treize, quatorze et quinze

$M$ 'a doucement de bien amer espris.

Pris a en moy une amoureuse prinse

Dis et sept, cinc, treize, quatorze et quinze.

Pour sa bonte que chascun loe et prinse

Et sa biauté qui seur toutes ont pris

Dis et sept, cinc, treize, quatorze et quinze

$M$ 'a doucement de bien amer espris.

Die Zahlen drücken die Buchstaben des Alphabets $R E N O P$ aus. Daraus folgt der Name Peronne mit Verdoppelung des $\boldsymbol{n}$ und $e$. Damit ist der Vorname der Dame gefunden. Sodann sollen in dem Anagramm am Schlurs des Gedichts die Namen des Dichters und der Dame enthalten sein (S. 370):

En la fin de ce livre prendre

Vous convendra le vers neuvisme

Et puis huil lettres de l'uitisme

Qui sont droit au commencement.

La verrez nos noms clerement.

Diese Verse lauten in der Ausgabe:

Pour li changier nule autre dame;

Madame le...

In den Handschriften steht aber für dame: fame. 
Tarbé hatte die Lösung gefunden: Guillaume de Machault et Agnes de Navarre, d'Evreus, de Champaigne, dame de Foi, und P. Paris: Guillaume de Machaut und Perone d'Armantiere.

Dafs diese Lösung, welche P. Paris giebt, unmöglich ist, hat Suchier gezeigt in Band XXI der Zeitschrift f. r. Ph. S. 54 I ff.

P. Paris hat allerdings wichtige Urkunden entdeckt, die seine Sache sehr zu stützen scheinen, in den Grands Officiers de la couronne in der Genealogie des Hauses Conflans: Le 4 novembre 1362, messire Jean de Conflans, pour sa belle-fille Peronnelle d'Unchair, fit aveu de la seigneurie d'Armentières au chapitre de Notre-Dame de Soissons.

Sonach ist im Jahre 1362 ein Fräulein Peronne d'Armentieres minderjährig, was mit dem im Gedicht angegebenen Alter von 15-20 Jahren übereinstimmt. Indes, so sehr beim ersten Anblick dieses Zusammentreffen überraschen mag, es will das nicht allzu viel besagen, wenn P. Paris nach langem Suchen, wie er selbst gesteht, in den Urkunden ein junges Fräulein Namens Peronne findet, die ihrem Alter nach zu den Angaben des Buchs pafst. Dafs der Familienname auch stimmen kann, ist nur durch eine Vergewaltigung des Textes möglich. Wenn man bei derartigen Anagrammen Aenderungen vornimmt, kann man allerdings viel heraus- oder vielmehr hineinlesen.

Um die Sache noch wahrscheinlicher zu machen und zugleich die etwa anzuführenden Gründe gegen das Unnatürliche des Verhältnisses wegen des verschiedenen Alters beider zu entkräften, führt P. P. das Verhältnis Goethes zu Bettina von Arnim an. Indessen, mag dies auch die mögliche Begeisterung eines jungen Mädchens für einen alten Dichter erklären, auch hier hat die Forschung erwiesen, dafs der Briefwechsel von Bettina gefälscht ist. Warum kann hier nicht das Umgekehrte der Fall sein, zumal dem Dichter dadurch ein spannender Stoff gegeben wurde, der ihn interessant machte und den Leser angenehm unterhielt.

Positive Angaben des Dichters über den Familiennamen der Dame liegen also nicht vor. Durch Urkunden können wir diese Frage kaum entscheiden. Es ist daher ein anderer Weg einzuschlagen, um die Schwierigkeit zu überwinden. Aus dem Innern des Buchs, aus der Art der Abfassung, dem Stil, sachlichen Angaben müssen wir zu erfahren suchen, ob Thatsachen dem Erzählten zu Grunde liegen, oder ob Mängel und Widersprüche im Inhalt und der Komposition, vielleicht noch andere Anzeichen uns dahin führen, das Ganze für reine Dichtung zu halten. Natürlich kann nur ein Wahrscheinlichkeitsbeweis geführt werden. Daher müssen wir zuerst zusammenstellen, welche Angaben über den Verlauf der Liebesgeschichte, über die Dame und ihre Familie, über sonstige Personen, Orts- und Zeitbestimmungen sich im Voir Dit finden. 


\section{Der Verlauf der Liebesgeschichte}

ist folgender nach den im Gedicht angegebenen und angedeuteten Thatsachen und Daten.

Es ist im Spätsommer des Jahres 1362 . In dem Garten seines schönen Besitztums sitzt der Dichter im warmen Sonnenschein, um sich von schwerer Krankheit zu erholen, da sein altes Leiden, die Gicht, ihn wieder hart angegriffen hat. In seiner beschaulichen Mufse denkt er über einen Gegenstand nach, der sein Dichterherz begeistern und zu Liebesliedern entflammen könnte. Doch hat seit sieben Jahren keine Liebe in seinem Herzen Einzug gehalten, er trauerte um ein verlornes Lieb. Da wird ihm jetzt durch einen langjährigen Freund, Namens Henri, den er lange nicht gesehen hat, ein Rondel von einer jungen, schönen und vornehmen Dame übersandt, worin diese ihrer Neigung zu Guillaume Ausdruck verleiht. Der Dichter ist dadurch aufs höchste beglückt, wird von seiner Krankheit ganz geheilt und ist sofort bereit, den angebotenen brieflichen Verkehr mit ihr einzugehen. Er antwortet mit einem Rondeau; bald folgt ein Brief von der Dame, den der glückliche Dichter sofort erwidert. $\mathrm{Da}$ der Bote aber nicht sogleich zu ihr zurückkehrt, bleibt der Liebende zwei Monate, bis zum Dezember, ohne Nachricht, was - wohl im Verein mit der winterlichen Witterung - ihn wieder aufs Krankenlager wirft. Neue Kunde von seiner Dame erweckt ihn aber zum zweiten Male vom Tode auf. Der poetisch-briefliche Verkehr wird fortgesetzt, Briefe und Gedichte gehen von ihm zu ihr, von ihr zu ihm. Der Dichter erhält von dem Fräulein auf seine Bitten ihr Bild, das er zu Häupten seines Bettes aufhängt. Er verspricht ihr, sie zu besuchen, nachdem seine Bedenken, daís sein Aeufseres einen ungünstigen Eindruck auf sie machen könne, von ihr durch einen liebenswürdigen Brief zerstreut sind. Die ursprünglich zu Ostern beabsichtigte Reise wird bis zur Pfingstzeit verschoben; sie wird mit einer Pilgerfahrt verbunden, die M.' in die Nähe des Aufenthaltsortes der Dame gelobt hat. Er hätte diese Wallfahrt noch lange nicht unternommen, nun dient sie ihm dazu, die Reise zum Fräulein zu verbergen. Die Dame befindet sich mit ihrer Schwester allem Anschein nach in Paris, wohin sie bei Beginn des Winters gegangen ist. N. tritt (Anfang Mai) seine Reise an, begleitet von seinem Sekretär und ein paar Dienern, und mietet sich in seinem Wallfahrtsorte ein, ein paar Stunden von dem Orte der Dame, der seine Ankunft natürlich sofort mitgeteilt wird. Der Dichter gelobt hier, während seiner neuntägigen Pilgerschaft täglich zu Ehren der Dame ein Gedicht zu machen. Sein Aufenthalt wird aber länger als er ursprünglich beabsichtigt hat, da der Dauphin ihn vierzehn Tage nachher zu sich nach Crecy, das nicht sehr weit entfernt liegt, entboten hat. Dem Liebenden ist diese Ver-

${ }^{1} \mathrm{M}_{\mathrm{.}}=$ Machaut. 
längerung durchaus nicht unangenehm. Die Dame wünscht dringend, ihn zu sehen. So begiebt er sich denn mit seinem Sekretär zu ihr. Anfangs äufserst erregt und bestürzt, so dafs er vor Verwirrung nichts sagen kann, überwindet er infolge des freundlichen Zuspruchs und der Liebenswürdigkeit der Dame endlich seine Schüchternheit. Das Zusammentreffen findet in einem Obstgarten statt in Beisein des Sekretärs und einer Gesellschafterin der Dame, die jedoch die beiden Liebenden nicht stört. Diese Zusammenkünfte im Garten wiederholen sich öfter. Der Dichter bleibt in dem Orte der Dame acht Tage. Dann beginnt er seine neuvaine von neuem. Die Dame trifft ihn bei einem mit mehreren Freundinnen unternommenen Ausflug, wo sie vom Regen überrascht worden sind, in seiner Wallfahrtskirche. Während der folgenden Tage findet ein eifriger Briefwechsel statt. M. will nach Beendigung seiner neuvaine wieder $\mathrm{zu}$ ihr kommen. Die Dame hat gerade an dem Sonntag, wo er wieder in ihren Ort kommt, mit ihrer Schwester eine dreitägige Reise in die Nachbarschaft unternommen. Der Liebhaber ist darüber sehr betrübt. Nachdem sie zurückgekommen, wagt er erst drei Tage lang nicht $z u$ ihr zu senden, bis er endlich durch den Sekretär einen Brief an sie schickt, worin er ihr schreibt, er glaube ganz von ihr vergessen zu sein. Die Dame läfst ihn sofort zu sich kommen. Er bleibt in ihrer Nähe drei Tage; dann reist er zu seinem Herrn, dem Dauphin, der in der Gegend von Crecy mit seinem Gefolge der Jagd obliegt. Er wird sehr ehrenvoll und freundlich aufgenommen. Erst nach vierzehn Tagen erhält er wieder Urlaub. Dals in der Zwischenzeit Briefe gewechselt werden, ist selbstverständlich. Vor seiner Rückkehr nach Reims will der Dichter noch einige Tage bei der Geliebten zubringen. Am ersten Abend haben sie eine Zusammenkunft in dem Garten, wo sie viel über ihre Liebe reden. Hier verabreden sic für den folgenden Tag eine Pilgerfahrt nach St. Denis, wo gerade der Lendit, der grofse Jahrmarkt, stattfindet. Die Dame wird von ihrer Schwester und einer Cousine, Namens Guillemette, begleitet. Nachdem sie dort in der Kirche ihr Gelübde erfüllt hat, was der eigentliche $Z$ weck der Reise war, gehen sie durch die Stadt und wollen von da aus nach Paris zurückkehren. Sie kommen durch La Chapelle, wo so viele Leute sind, dafs nirgends ein Unterkommen zu finden ist. Das Fräulein ist durch die Sonnenglut sehr müde geworden und möchte gern ausruhen. Da finden sie endlich durch Vermittlung eines angeheiterten Sergeanten ein Haus am Ende der Stadt, wo ihnen ein Zimmer mit zwei Betten zur Verfügung gestellt wird. Die Schwester benutzt sofort das eine. Der Dichter will draufsen warten; doch er mufs sich trotz seines Sträubens in das andere zwischen die Dame und deren Cousine legen. Nach der None stehen sie auf. Sie treffen sich mit Bekannten in einem Konzertgarten, wo sie den Abend mit Spielen und Anhören der Konzertgenüsse hinbringen. Die Damen werden schliefslich mit Fackeln nach Hause gebracht. Das war am 12. Juni 
1363. M. bleibt noch sieben Tage in Paris, in stetem Verkehr mit der Dame. Endlich kommt der Tag, wo es gilt Abschied von ihr zu nehmen. $\mathrm{Da}$ ihm das Scheiden so schwer wird, bescheidet die Dame ihn noch am Morgen seiner Abreise zu sich, empfängt ihn in ihrem Schlafgemach und giebt ihm die höchsten Beweise ihrer Liebe, händigt ihm ein goldenes Schlüsselchen zu ihrem tresor ein, während er ihr einen Ring schenkt. Dann scheidet er endlich. Er reitet den ganzen Vormittag; bevor er aber zu Mittag ifst, schreibt er schon an die Geliebte und wartet hier auch die Antwort ab. Trotzdem das Land unsicher ist von Plünderern und sie in grofser Gefahr sind, da eine Bande erscheint, die wohl dem Erzpriester mit seinen Bretonen, der damals das Land unsicher machte, angehörte, gelangen sie (der Dichter und seine Begleiter) wohlbehalten nach Reims. Hier im Schutze der starken Mauern fühlt sich M. erst wieder sicher und ist froh, sein behagliches Heim erreicht zu haben. Nur die Sehnsucht nach ihr und der Wunsch, so schöne Stunden nochmals zu durchleben, regt ihn auf und lärst ihn Gedichte schaffen und Briefe schreiben, die von der Dame bald erwidert werden. Sie freut sich auch, da/s er den Gefahren glücklich entgangen ist. Während ihres Zusammenseins hat er mit ihr verabredet, die Geschichte ihrer Liebe in einem Gedichte ganz nach der Wahrheit zu schreiben, dabei auch alles, was sie sich zugesandt haben, einzuflechten, damit ihre Liebe besonders zum Ruhme der Dame bekannt werde. In seiner stillen Mufse nun beginnt er mit der Verwirklichung dieser Idee und arbeitet voll Eifer, ihr später von dem Fortgang des Werkes immer berichtend, auch Proben übersendend. Ihre gemeinsame Reise ist aber nicht unbemerkt geblieben. Bald verbreitet sich unter den vornehmen Kreisen die Märe von der Liebe des greisen Dichters zu dem siebzehnjährigen Edelfräulein. Das ist entschieden interessant. So kommen denn zu dem Klerikus in Reims vornehme Herren und fragen, ob clas grofse Glück wahr sei, verlangen auch Briefe und ihr Bild zu schen. Ihr Lob ist in aller Munde; wohl nicht ohne heimlichen Spott preisen sie des Dichters hohes Glück durch die Licbe zu der herrlichen Maid. Die Dame freut sich, als sie das erfährt, und wünscht selbst Mitteilung ihres sülsen Verhältnisses, damit alle Welt davon Kunde erhalte. Während sie bis jetzt immer bei ihrer Schwester war, wird sie nun von ihrem Geliebten gebeten, nach Reims zu kommen zur St. Nichaise, da er vernommen, dals die Schwester dahin eine Wallfahrt für ihre Kinder machen will. Der Bruder der Dame, Th., wird sie mit ihm zusammen bei der Porte saint Antoine treffen. Sie will auch wirklich Mitte August an den vom Boten näher bezeichneten Ort kommen; doch soll er nicht schreiben, bevor er Nachricht von ihr bekommen. Denn wegen einer Epidemie muls sie und ihre Schwester Paris verlassen und weifs den künftigen Aufenthaltsort noch nicht genau. Des Dichters Geduld wird auf eine harte Probe gestellt: es vergehen mehrere Wochen, nach andern Angaben über zwei Monate, ohne dafs er 
etwas von der Dame hört. Endlich am 27. September kommt wieder ein Brief. Sie befand sich schon seit 20. August an dem neuen Aufenthaltsorte, den sie gewählt hat nach Verlassen von Paris. Sie hat dann ihres Bruders Güter mit der Schwester zusammen besucht, ist dort vierzehn Tage geblieben und natürlich noch in der Champagne. Der Bruder der Dame, der an den Königshof geht, kehrt am Michaelistage bei Machaut ein und wird sehr ehrenvoll bewirtet. Die Dame ist jetzt vielleicht in Troyes oder Châlons (da eine Peterskirche in dem Ort ist, an deren Pfarrer der Dichter seine Briefe senden soll). Es ist auffallend, dafs die Dame ihre Beziehungen zu dem Geliebten möglichst geheim zu halten sucht, vor allem auch ihrem Bruder als eine harmlose Korrespondenz hinstellt. In Reims ist im Oktober der König, so dals aufserordentlich reges Leben da herrscht. In des Dichters Hause wohnt der Herzog von Bar, so dals der Dichter nicht viel an seinem Buche arbeiten kann. Wenn die Gegend sicherer ist, will das Fräulein, die jetzt bei ihrer hier zum ersten Mal erwähnten Mutter wohnt, mit ihm zusammentreffen, sie schreibt ihm, dafs er an ihren Aufenthaltsort mit dem Sekretär kommen soll. Alle trennenden Hindernisse sind beseitigt, doch müssen sie sehr vorsichtig sein. Der Dame Gefährtin Columbelle soll unter Umständen ins Vertrauen gezogen werden, der Sekretär ist auf alle Fälle nötig. Der Dichter, der Anfang November eine Reise nach St. Quentin und zum Herzog der Normandie geplant, aber wegen Kriegsgefahr nicht unternommen hat, ist bereit, im November - die Dame schreibt am 13. - zu ihr zu gehen und ruft deshalb den Sekretär, welcher drei Tagereisen entfernt ist, schleunigst zu sich. Es herrscht in diesen Tagen ein furchtbarer Sturm, wie er seit 60 Jahren nicht gewesen ist; der Sekretär weigert sich, bei diesem Unwetter, zumal da auch durch Banden das Land unsicher gemacht sei, mitzureisen und warnt seinen Herrn eindringlich. Dieser will die Reise trotz alledem antreten. Während sie noch zu keinem Entschlufs gekommen sind, kommt ein vornehmer Herr, wohl ein Baron der Champagne, und teilt dem ihm befreundeten Dichter mit, dafs dieser von seiner Dame in schändlicher Weise hintergangen werde. Denn diese mache sich im Kreise einer Menge junger Anbeter über ihn lustig und zeige allen seine Briefe. Der Liebende ist dadurch aufs tiefste getroffen. Schon ein anderer Freund hat ihm geschrieben, er solle ablassen von dieser ungleichen Liebe. Der Sekretär hält nun mit seiner Ansicht auch nicht zurück, so dafs der Dichter endlich die Reise aufgiebt und beschliefst, das Verhältnis aufzulösen, doch nicht plötzlich, da er sich ihr zu grofsem Danke verpflichtet fühlt. Tiefer Gram erfarst ihn, er sagt allen Freuden Lebewohl, mufs auch die trübe Erfahrung machen, beim Herzog, zu dem er später reitet, und sogar auf der Strafse wegen seiner getäuschten Liebe ausgelacht und verhöhnt zu werden. Ganz verstört reitet er heim; ihm wird erzählt, dals sie ihn vergessen habe und sich mit einem andern ergötze. So schreibt er nicht 
wieder an sie, bleibt den ganzen Winter einsam und zurückgezogen zu Hause; ihr Bild legt er in eine Truhe. Jedoch die Dame sucht wieder anzuknüpfen; den Briefen nach zu urteilen, scheint der Hauptgrund die Furcht zu sein, dafs dieser plötzliche Bruch ein schlechtes Licht auf sie werfen und ihrem Rufe schaden könne. Das Buch, welches ihre Liebe schildert, ist allerdings ziemlich vollendet; es soll aber doch einen guten Abschlufs finden. So schreibt sie, wohl im Frühjahr 1364, einen Brief, worin sie sich als gekränkte Unschuld hinstellt, ihm Untreue vorwirft und ihn dringend bittet, ihr wieder hold za sein. Der Dichter schreibt ihr nichts von dem, was er vernommen hat. Doch endlich wird ihm dieser Zustand unerträglich. Im Juni darauf teilt er ihr das Vernommene mit, wenn auch in schonender und milder Form. Die Dame ist über diesen Brief und über ein Gedicht, worin er ihre Veränderlichkeit beklagt, sehr bestürzt. Sie beteuert ihre Unschuld und schickt später sogar einen Priester, dem sie alles gebeichtet hat, an den Freund, damit er die Beichte letzterem mitteile. Der Priester, welcher ein guter Bekannter des Dichters ist, weifs ihn von der Schuldlosigkeit des Fräuleins zu überzeugen und zu der Ansicht zu bringen, dafs er vorschnell unwahrem Gerede geglaubt hat. Infolge dessen ist der getreue Liebhaber wieder versöhnt; alles soll vergessen und vergeben sein. Die Dame, welche ihm durch den Sekretär noch ein ganz intimes Liebesgeschenk übermittelt hat, was seine höchste Mifsbilligung findet, schreibt zum Schlufs, dafs sie sich sehr freue, dafs ihre Freundschaft in der alten Weise wiederhergestellt sei. Indessen wird eine Fortsetzung der brieflichen Beziehungen in der bisherigen Art doch nicht gewünscht. Der Dichter schickt die clef $d u$ tresor zurück; das Buch ist vollendet.

Hiermit schliefst die Geschichte. Der Schlufs deutet darauf hin, dafs dic Dame andere Beziehungen hat, die ihr nicht gestatten, das Verhältnis mit dem Dichter in der bisherigen Weise fortzusetzen.

\section{Die Dame und ihre Familie.}

Aus dem Gedichte erfahren wir etwa Folgendes ïber dis Persönlichkeit der Dame, die Machaut verherrlicht, über ihre Stellung und ihre Familienverhältnisse.

Nach dem Rondel auf S. 266 ist ihr Name Peronne. Sie ist I5--20 Jahre alt, nach S. 84 :

\section{elle of de quinze a vint ans \\ dont je la prise mieux vint tans.}

Dafs sie aus einer vornehmen Familie stammt, zeigt das zahlreiche Gefolge, das sie hat, ferner der Umstand, dafs ihr Bruder am Hofe des Königs verkehrt und viel vornehmer ist als Machaut, sodann der Vergleich mit Esperance S. I81, wo der Dichter er- 
zählt: Esperance estoit une si noble dame et aussi il me souvint plus ardemment de vous pour ce qu'elle estoit dame moult noble.

Ihr Vater ist jedenfalls tot, da er nie erwähnt wird. Die Mutter wird erst S. 282 erwähnt: envoiez par devers moy en l'ostel de ma mere ... Et s'il trouvoit en l'ostel de ma mere aucune personne qui li demandast dont il venoit qu'il deist qu'il venist de ma suer. Bisher schien es immer, als sei sie unter der Obhut ihrer älteren Schwester. Nur diese eine Schwester wird erwähnt, sie ist verheiratet und hat Kinder, vgl. S. 204.

Die Schwester begleitet die Liebenden auf dem Ausfluge nach St. Denis. Sie kennt zwar nicht ganz die Art des Liebesverhältnisses, doch steht sie beiden freundlich gegenüber, weifs von dem Briefwechsel und der grofsen Neigung des Dichters. Bezeichnend ist die folgende Stelle, S. 208: Ma suer se recommande a vous assez de fois et vous desire moult a veoir. Elle vint a moy quant je faisoie ces lettres et me demanda se jescrivoye a mon amy, et je lui respondi qu'oill; et elle me dist: Recommendez moy a lui beaucoup de fois; car je le veisse volontiers.

Ferner wird in dem Gedicht an verschiedenen Stellen ein Bruder von der Dame erwähnt, zuerst S. 48: J'ai receü les lettres que vous envoies a mon frere. (49) aussi mes dis freres n'est pas au paÿs, car il se parti de moi le huitieme jour de decembre, pour aler en Avignon; et, re dit jour, lui et vostre secretaire dirent nouvelles de vous. Weiter finden wir den Bruder auf S. 204 erwähnt: T., vostre frere, venra avec moy. S. 233 sehen wir, dals er Güter besitzt in der Landschaft Brie: nous partismes pour aler en Brie pour veoir les maisons de non frere. S. 235 wird angeführt, dafs er zum König reist. Dieser Bruder, der mehrfach mit $T$. oder $T h$. bezeichnet wird und jedenfalls Thommas heifst, da man S. 268 J'ai veu ce que vous m'avez escript de Thommas auf ihn beziehen muls, ist mit dem Dichter bekannt und kehrt in seinem Hause ein, S. 240. $\mathbf{E r}$ scheint einerseits über das Verhältnis der Dame mit Machaut unterrichtet zu sein, da er Briefe zwischen beiden vermittelt, andererseits ist in einigen Teilen des Gedichts die Dame ängstlich bestrebt, die Sache vor ihm als einen harmlosen Briefwechsel hinzustellen, S. 235: ne li monstrez pas vostre ymage... Mais je vueil que vous li dicles un po et non pas trop que vous m'amez et pour ce que je chante volontiers.

Die Dame wechselt mehrmals ihren Wohnsitz; längere Zeit scheint sie in Paris zu sein, dann wieder auf Gütern in der Champagne und in verschiedenen Städten dieser Provinz. - Sie hat grofses Interesse an der Dichtkunst; nicht mit Machaut allein steht sie in litterarischer Verbindung, vgl. S. 207: je n'en vueil nuls chanter que des vostres; et si m'en aporte l'en bien souvent; mais je ne vucil mettre peine a les apenre, car il m'est avis que tout ce que les autres font ne vault riens a regarder ce qui vient de vous. Sie dichtet ja auch selbst, und nach den Gedichten im Voir Dit, welche von ihr herrühren - nach Angabe des Dichters -, muls ihr Talent ziemlich 
bedeutend sein. Dabei lernt sie sehr leicht auswendig und ist nach S. 4

\author{
la mieulz chantans
}

Qui fust nee depuis cent ans.

An dieser Stelle wird sie genauer geschildert. Nach den Worten des Boten mufs sie ein liebreizendes Geschöpf sein:

En ce roiaume ha une dame,

Gente, juene, jolie et joincte,

Longue, droite, faitice et cointe,

Sage de cuer et de maniere,

Tres humble et de tres simple chiere,

Belle, bonne et la mieulz chantans

Qui fust nee depuis cent ans;

Mais elle danse oultre mesure;

Et s'est si douce creature

Que toutes autres vainc et passe

En sens, en dougour et en grace.

Allerdings wird sie auf S. 30I als sehr kokett und gefallsüchtig, tändelnd mit einem ganzen Kreise junger Verehrer hingestellt. Doch trotzdem tadelt sie der Redende im allgemeinen nicht:

Car elle est bonne et preude femme,

Sage, honneste, cointe et aperte

Et n'est ombrage ne couverte.

Weitere Angaben über sie sind nicht gemacht. Alles, was man sonst dem Gedichte über sie entnehmen wollte, beruht nur auf Vermutung. Trotzdem aber die Dame sehr anschaulich und mit lichevoller Wärme geschildert ist, dürfte es aus dem oben Angegebenen doch ziemlich schwer sein, eine bestimmte Persönlichkeit, etwa die Peronne von Armentières, herauszufinden. Auch die sonstigen Angaben von Personen helfen dazu nichts.

\title{
Personennamen.
}

I) im Voir Dit vorkommenden Personennamen sind nicht zahlrcich; meist nur kurze Angaben sind über die genannten Persönlichkeiten gemacht, so dals man aus ihnen nicht viel entnehmen kann. Wir finden folgende Namen.

1. Henri, Freund Machauts und der Dame, S. 3, 8, 195, 268, 282, 314. Dieser nimmt bei der Dame die Stellung eines Vertrauten ein; er ist es, der dem Dichter das erste Rondel von der Dame bringt, vgl. S. 195: H., vostre amis, ha esté a Paris, il se recommande a vous moult de fois, si a grand joie de vostre bien et du mien et metteroit volontiers peine comment nous en eussions plus. Et .. nous le devons amer, car c'est cils par quoy nos amours furent premiers commenciés.

P. Paris nimmt an, nach der Schilderung vom Zusammentreffen des Dichters mit dem ersten Boten (S. 3-8, 10), dals dieser an 
Rang niedriger steht. Aber Seite 314 schreibt der Poet: Recommandes moy a $H$., quant vous le verres. Et certes, se il me povoit venir querre je seroie honnorez et si seroit moult la pais de mon frere. Das spricht wohl nicht für seine Behauptung. Wer dieser Freund ist, wissen wir nicht: vielleicht ist ihm das von P. Paris erwähnte Gedicht gewidmet, wo M. über die Unbilden, die ihm in Reims widerfahren sind, klagt. Doch bringt uns das in unserer Untersuchung nicht weiter.

2. Guillemete, Cousine der Dame, S. 143, 146.

3. Colombelle, S. 283, 314.

4. Bernart de Flourent, frère du curé de S. Pierre, S. 259, 262, eine sonst unbekannte Person.

5. Le duc de Bar, S. 259, 262, der während des Aufenhalts des Königs in Reims beim Dichter gewohnt hat.

6. Le duc de Normandie, der Dauphin, Machauts Herr und Gebieter, der ihm sehr gewogen ist; S. 71, I $31,132,136,139,307$.

7. Von P. Paris wird ein Dichter Thibaut Paien angeführt, der mit M. einen dichterischen Wettstreit gehabt hat. Die beiden Streitgedichte werden der Dame zur Begutachtung vorgelegt, damit sie den Schiedsspruch fällt. Tarbé schreibt das eine Gedicht, das M.s Gegner gemacht hat, dem Bruder der Dame, Thommas, zu, S. 132 seiner Ausgabe. In den Handschriften $\mathrm{A}$ und $\mathrm{C}$ ist dieses Gedicht auch mit Thomas überschrieben, während das andere den Verfassernamen Machaut trägt. In Hs. B ist es nur mit Balade überschrieben. $\mathrm{Ob}$ mit diesem Th. nun der Bruder der Dame gemeint ist, was Tarbé wohl aus Brief 36 schliefst: j'ay bien veu ce que vous m'avés escript de Thomas, wo es sich wirklich um den Bruder der Dame handelt - indes braucht die Stelle nicht auf das Gedicht sich zu beziehen -, oder ob darunter ein anderer zu verstehen ist, kann man schwerlich entscheiden. Der Zusatz Paien deutet eher auf das letztere hin. Warum aber P. Paris den Namen Thibaut einführte, ist nicht ersichtlich. Die ganze Stelle lautet nach S. 266: Je vous envoie la balade T. Paien, et la response que je li fais, laquelle je fis en present; mais il fist devant et prist toute la graisse du pot a son pooir, et la fis apres.: si en jugerez, sil vous plaist. Mais vraiement il avoit l'avantage de trop, et toutevois je $y$ feray chant.

8. Tarbé führt als Personennamen Jehane an, der in einem Rondel versteckt enthalten sei, S. 170, 17 I seiner Ausgabe. Er vermengt indes in der Lösung das 2. und 3. angeführte ,énigme', so dafs er das zweite, das S. 266 im Voir Dit steht, vergifst und die Lösung des dritten, welches nicht im Voir Dit ist, zum zweiten nimmt. Demnach fällt dieser Name fort.

\section{Ortsangaben.}

Ebenso wie mit den Personennamen verhält es sich mit den Ortsangaben, sie sind mit Absicht grörstenteils fortgelassen oder so 
allgemein und unbestimmt, dafs auch damit keine wesentlichen Momente für die Bestimmung der Dame beigebracht werden können.

An geographischen Namen finden sich folgende:

1. Conte de Fois und Lorraine, S. 47.

2. Gascogne, S. $5 \mathrm{I}$.

3. La ville de Crecy, S. I 36.

4. Saint-Denis, S. $142 \mathrm{ff}$.

5. Sainte-Jame, S. $143 .^{1}$

6. La Chapelle, S. I44.

7. Paris, S. 144, I 95 u. a.

8. Saint-Nichaise da Reims, S. 204.2

9. La Brie, S. 233.

10. Saint Quentin, S. 266.

II. Biau chastel, S. 345 .

12. Ein Ort wird erwähnt, in dem sich eine Peterskirche befindet, S. 250.

Aus I und 2 könnte man schliefsen, dafs die Dame, deren Bote von Fois nach Lothringen geht (le vallet de Gascogne) sich in Südfrankreich aufhält. Nach den Angaben der Erzählung wechselt sie bei Beginn des Winters $(1362 / 63)$ ihren Aufenthalt. In dem Ort, den sie jetzt aufsucht, bleibt sie bis zur Zusammenkunft mit dem Dichter und noch länger. $\mathrm{Da}$ dieser in der Nähe von Paris seinen Wallfahrtsort hat (vgl. Angaben 3-7) und die Damen nach dem Lendit auf dem Rückwege von St. Denis durch La Chapelle, das zwischen Paris und St. Denis liegt, kommen, am Abend Bekannte treffen und noch dieselbe Nacht an ihren gewöhnlichen Aufenthaltsort zurückbegleitet werden, so müssen sie in Paris wohnen. Vgl. auch S. 195, wo Henri nach Paris gekommen ist und der Dame Grüfse an Machaut aufgetragen hat. Die Angaben über dic Pest stimmen dazu auch, S. 2 I I:

\section{elle estoit departie \\ Pour cause de l'epidimie, \\ Dou lieu ou fu sa demourie, \\ Ains alu en autre contree.}

Sie ist mit ihrer Schwester in die östlicheren Provinzen gegangen, mehr in die Nähe von Reims. Ihr Bruder in der Brie wird auf seinen Landgütern besucht, dann hält sich die Dame an einem Orte auf, in dem eine Peterskirche sich befindet (P. Paris meint, in Châlons-sur-Marne oder Troyes). Sie verändert den Wohnsitz abermals, S. 279, Je seray, ou vous savez, dedens huit jours und befindet sich dann nach S. 282 bei ihrer Mutter. Die Entfernung von Reims ist nicht grofs, da ein Brief binnen zwei Tagen beant-

1 Ein Ort Sainte-Gemme liegt in der Nähe von Reims. Vgl. die Ausgabe von $P$. Paris. zerstört.

2 Die Kirche St.-Nicaise in Reims wurde während der Revolution 
wortet ist. Im Herbst 1363 wäre sie der Angabe auf S. 345 nach in Biau chastel. Nach S. $3^{1} 3$ wohnt sie noch in der betreffenden Stadt, von wo sie früher an den Geliebten geschrieben hatte. Die übrigen Ortsangaben sind unwesentlich. Für die Datierung der Briefe und die Vergleichung der Zeitangaben ist es aber von Wichtigkeit, den Aufenthaltsort der Dame wenigstens ungefähr zu kennen. Das ist meines Erachtens nach die Hauptbedeutung der Ortsangaben für das Gedicht; denn etwas Spezifisches, was nur auf eine bestimmte Person gedeutet werden könnte, findet man sonst in den Angaben nicht.

Die Zeitangaben kommen erst in zweiter Linie zur Ermittlung der Dame in Betracht, sie werden in anderm Zusammenhang behandelt. - Wir sahen bisher, dafs mit den im Gedicht gemachten Angaben über die Dame nichts Gewisses zu ermitteln ist. Im Gegenteil sind die Angaben so unsicher, dafs die beigebrachten Urkunden keinen Beweis für P. Paris' Behauptung liefern können. Fehlen uns aber äufsere Handhaben, so sind wir auf das Gedicht allein angewiesen und haben aus dem Innern heraus zu prüfen, ob historische Echtheit des Erzählten und der Briefe wahrscheinlich ist oder nicht. Wir müssen dabei Zeit der Abfassung, Art der Abfassung und etwa in Komposition, Stil, sachlichen und zeitlichen Angaben erscheinende Besonderheiten bezw. Widersprüche betrachten.

\section{Abfassungszeit des Gedichtes.}

Um das Jahr der Abfassung feststellen zu können, hat man verschiedene historische Angaben aus dem Werke heranzuziehen, die in der lateinischen Continuatio der Chronik des Guillaume de Nangis von Jean de Venette ihre Bestätigung finden. P. Paris hat in der Vorrede seiner Ausgabe gezeigt, dafs die Abfassungszeit des Voir Dit in die Jahre $1363-1365$ fällt, und er hat die Ansicht, dafs das Werk 1348 entstanden sei, die Tarbé ausspricht (vgl. S. 145), widerlegt. Es ist überfüssig, die beweisenden Stellen nochmals aufzuführen. Was nun das genauere Datum, an dem die Arbeit begonnen wurde, anbetriff, so bin ich zu einem etwas andern Ergebnis als P. P. gekommen. Mafsgebend ist nämlich eine Stelle des Briefes 27, der laut Datum am 8. August (1363) geschrieben ist. Die Stelle lautet: Je vous envoie une balade qui fu faite au bout du mois que je me parti de vous. Et puis je commençai vostre livre. $M$. beginnt also mit der Abfassung des Buches, nachdem er die Ballade komponiert hat. Diese ist, wie er sagt, einen Monat nach seiner Abreise von der Dame gedichtet. Letztere zu datieren ist nicht schwer. Wir gehen aus von dem Lendit zu St. Denis, dem I 2. Juni. Nach diesem bleibt der Dichter noch sieben Tage bei der Dame, S. I5I:

La demouray sept jours en route, A grant deduit, moy et ma route. 
Sodann

Finablement li termes vint

Er dürfte also am 20. Juni abgereist sein. Die Ballade ist gerade einen Monat später gedichtet; sie beginnt (S. 264):

\section{Hui ha un mois que je me departi}

De celle en qui j'ay toute ma cure.

Nan kommt also ungefähr auf den 20. Juli. Das stimmt überein mit zwei Stellen auf S. 238 und 242, wo er in Bezug auf sein Buch sagt: j'en ay plus fait depuis la Magdeleine que je ne cuidoie faire en un an entier. Ohne Grund hat er diesen Tag, den 22. Juli, sicher nicht genannt. Vergleichen wir damit den Anfang des Buchs S. 2: Il n'a pas un an que j'estoie..., so kommen wir dort auf die Monate August oder September, was ganz gut stimmt. Dazu kommt S. 191 folgende Stelle: me suis remis a faire vostre livre en quel vous serés loee el honnouree de mon petit pooir. In nächsten Brief der Dame wird zum ersten Mal darauf Bezug genommen - vorher spricht diese nie von dem Werk - und die hohe Freude ausgedrückt, die sie darüber hat. Dieser Brief ist aller Wahrscheinlichkeit nach Ende Juli geschrieben. Indes steht damit S. I 34 (Br. I7) in Widerspruch: Toulefois, je fais en vostre livre ce que je puis. Auf Grund dieser Stelle nimmt P. P. an, dals Machaut schon früher mit dem Werk begonnen hat. Er will obige Stelle, wo M. von seiner Abreise spricht, damit so in Einklang bringen, dals er sagt, der Dichter habe das Buch nach seiner ersten Trennung von der Dame begonnen, als er zum Herzog ging. Dann mufs man sich aber wundern, dafs er die in Frage kommende Ballade nach seiner Rückkehr nicht selbst übergiebt, sondern viel später sendet. Aufserdem stimmt ihr Ton und Inhalt dazu nicht. Denn rechnet man von dieser ersten Abreise vier Wochen weiter, so findet man einen Zeitpunkt, an dem er wieder bei ihr weilt, also hat er da gar keinen Grund zu einem Klagelied, dafs sie getrennt sind; hat er doch auch versprochen, bald wieder zurückzukehren. Die endgültige Abreise stimnt aber zu dem Platze, wo das Lied steht, zu dem Anfang der Ballade und vor allem auch zu der Schlufsstrophe, die lautet:

Et sans doubtance onques puis je ne vi

Riens qui peüst mettre en envoisure

Moy ne mon cuer; et c'est droit, que sans li

$\mathrm{Ne}$ quier avoir nulle bonne aventure,

Ne joie, n'alligement;

Car a li suis donnés si ligement

Que je ne fis onques puis chiere lie,

Tant me fist mal de li la departie.

M. giebt also selbst an, er habe seitdem keine Freude wieder gehabt; das würde doch der Wirklichkcit nicht entsprechen, ebenso- 
wenig wie in Str. I der Anfang, dafs er vier Wochen getrennt ist, während er nach wenigen Tagen schon zurückkommt. Es liegt hierin ein offenbarer Widerspruch, der auch keine rechte Erklärung findet, wenn man zwischen Entwurf und Ausarbeitung unterscheidet. Die oben angeführten Gründe sprechen aber dafür, dals der Dichter das Werk Ende Juli 1363 begonnen hat (nach den Angaben im V. D.). 1

Im Anschlufs daran sei auf zwei Stellen aufmerksam gemacht, S. 62 und 69, wo auch schon von vostre livre und mon livre die Rede ist. Damit kann le livre du voir dit nicht gemeint sein. Die Dame schreibt nämlich: vueilliez moi envoier vostre livre le plustost que vous porrés, car je ne pren plaisance ne esbatement que en vous et en vos choses.

Dazu lautet die Antwort auf S. 69: je vous eusse porte mon livre pour vous esbatre, ou toutes les choses sont que je fis onques. Mais il est en plus de vingt pieces; car je l'ay fait faire pour aucun de mes seigneurs; si que je le fais noter, et pour ce il convient que il soit en pieces. Er sagt also ausdrücklich selbst, dafs es eine Gesamtausgabe seiner Werke ist.

Fortschreitend mit der Erzählung schreitet dann auch die Vollendung des Buches vorwärts, in unmittelbarem Zusammenhang mit den Ereignissen. In Brief 45, der vom 10. April - es ist das im vierten Jahre nach Beginn des Liebesverhältnisses - datiert ist, schreibt der Dichter, das Buch werde in vierzehn Tagen fertig gestellt. Es ist sonach im Frühjahr 1365 zum AbschluIs gebracht, und der Dichter hat vom Juli 1363 bis zum April I 365 daran gearbeitet. 1

\section{Art der Abfassung. Stil.}

Das Buch ist in paarweise gereimten Achtsilblern abgefalst. Dazwischen eingefügt sind 45 Briefe in Prosa und eine Klageepistel in Versen, 23 vom Dichter, 23 von der Freundin; aufserdem sind eingefügt 29 Gedichte Machauts an die Dame, nämlich 14 Rondels, 8 Balladen, 5 Chansons baladees, I Lay, I Complainte. Von der Dame sind 26 Gedichte an den Freund gesandt, I 5 Rondels, 6 Balladen, 3 Chansons baladees, 2 Complaintes. Dazu kommt ein Gesang des Dichters an Venus, die Antwort auf die Ballade Th.s und die Ballade Th.s, so dals im ganzen 58 Gedichte im Voir Dit enthalten sind.

Der Zweck des Werkes ist eine Verherrlichung der Dame (vgl. Brief 25) und ihrer Liebe, von der man noch nach hundert Jahren reden soll. Ueber die leitenden Motive bei der Abfassung spricht sich der Dichter selbst mehrfach aus. So erklärt er auch zuerst S. 17 den Titel:

\section{Le Voir Dit vueil je qu'on appelle \\ Ce traictie que je fais pour elle, Pour ce que ja n'i mentiray}

$1 \mathrm{Ob}$ diese Angaben der wirklichen Zeit entsprechen, wenn das ganze Gedicht auf Ertindung beruht, ist eine andere Frage. 
und ebenso S. 263: Voir Dit ara le nom, pour ce que ja ni doi ni vueil mentir.

Er entschuldigt sich oft, dafs er vielleicht zu viel erzähle. S. 16 spricht er aus, dafs es der Befehl der Dame sei, alle Briefe, sülse und herbe, wiederzugeben. Ihren Wunsch muls er erfüllen. Manchem könne einiges auffallend und anstölsig sein, doch ist ihm das gleichgültig. Wenn etwas zweimal gesagt oder geschrieben sei, brauche man sich nicht zu wundern; denn seine Dame wolle, dafs alles der Wahrheit gemäls erzählt werde. So S. 84/85:

Ce n'est pas trop grant villenie,

$S$ 'en ce livre riens mettre n'ose

Qu'ainsi comme il est, et sans glose.

Car contre son commandement

Feroie du faire autrement:

Et puisqu'il li plaist, il m'agree

S. 128:

S'obeiray a sa pensee.

Or vous diray ce qui m'avint

Et a quel chief cest amour vint;

Car ma douce dame le vuet;

Quant il li plaist, faire l'estuet.

Er stattet der Dame in den einzelnen Briefen immer Bericht über das Fortschreiten seiner Arbeit ab, so S. 202: Vostres livres se fait et est bien avanciés; car j'en fais tous les jours cent vers et, par m'ame, je ne me porroie tenir du faire, tant me plaist la matere. Die Briefe, die er der Dame sendet, läfst er sich später immer zurückschicken, um sie gleich dem Buche einzuverleiben. Die früheren Sendungen nimmt er von (St. Denis) Paris aus mit nach Reims, trägt sie da in das Buch ein und schickt sie dann zurück, vgl. S. 242: Je vous envoie la laietle que vous me baillastes au partir de vous, et tout ce qui est dedens, car tout est mis par ordre dedens vostre livre. Da indessen zuerst das Datum nicht beigefügt war, findet er schwer das Richtige zusammen, S. 202/3: j'ay trop a querir les lettres qui respondent les unes aus autres. Die Dame erhält von Zeit zu Zeit das Fertiggestellte, damit sie es liest und Verbesserungen anbringt. Wenn sie nun einmal etwas auszusetzen hat - im allgemeinen hat sie grofse Freude am Ganzen -, so schreibt sie es doch nicht in den Briefen, sondern sagt stets, sie wolle das Betreffende ihm mündlich mitteilen. Das ist immerhin etwas sonderbar. Einfacher ist es doch, es gleich schriftlich $z u$ thun. Indes würden dann die Briefe die zu verbessernden Stellen eines Buches angeben, in das sie selbst eingefügt werden sollen, und würden nicht wohl in dieser Gestalt ihren Platz darin finden können. Man sieht hieraus, dafs schon bei der Abfassung der Briefe weniger die natürliche Empfindung als der Gedanke vorherrschend ist, dafs der ganze Briefwechsel für die Oeffentlichkeit bestimmt ist, wie S. 263 der Dichter schreibt, er müsse alle seine Empfindungen in den Briefen aus-

Zeitschr. f. rom. Phil. XXII. 
drücken, da diese in das Buch kommen sollen; denn der Titel verlange das. Seine Empfindungen und sein Denken stehen also auch hier unter dem Einflurs, den die Rücksicht auf das für die Oeffentlichkeit bestimmte Buch auf ihn ausübt. Das ist immerhin bedenklich.

Sehr auffallend ist im allgemeinen an den Briefen und Gedichten, welche der Dame zugeschrieben sind, die grolse Aehnlichkeit des Stils mit dem Machauts. In den Gedichten kann das ja an und für sich nicht so sehr zu Tage treten als in den Briefen, da in ersteren dem Dicher durch die Reime und die Silbenzahl Schranken auferlegt sind und er sich nicht so frei mit seinen Ausdrücken und Wendungen bewegen kann wie in den Briefen. Besonders wird ein Vergleich der Gedichte in dieser Hinsicht noch dadurch erschwert, da「s vielfach Machaut und die Dame ausdrücklich dieselben Reime und dasselbe Versmals anwenden. Indes finden sich in den Gedichten der Dame Anklänge genug an Machaut, so folgende:

D. (Dame) S. 56. .. suis tousdis en grant merencolie.

M. (Machaut) S. 65. . . est en grant merencolie.

D. 56. Dont souvent ay estrangle maint souspir.

M. 67. Dont maint souspir me convient estrangler.

D. 56. Qu'apres ma mort m'ame vous amera.

M. 71. Et aprés mort mon ame l'amera.

D. 246. T'amoie plus que my $\mid$ De cuer entier.

M. 37. .. s'aim de fin cuer entier.

D. I 19. si me devez tenir pour excusee

M. I I 2. que vous me vueilliez tenir pour excusé.

D. 56. Or veuilliés dont entendre ma clamour - : amour.

M. 184. Oy de ton ami la clamour: amour.

D. 166. Merveille fu quant mon cuer ne parti.

M. 204. Car a peine que mes cuers ne parti.

D. 166. Car tel dolour onques mais ne senti.

M. 204. Mais onques mais mes las cuers ne senti|

Nulle dolour - si dure.

D. 56. Mes dous amis a vous me veuil je plaindre, Dou mal qui fait mon cuer palir et taindre.

M. 220. Rois, je m'en vieng a toy complaindre Des maus d'amour qui me font taindre.

D. 56. . fait mon cuer palir et taindre.

M. 237. j'eus le cuer taint et pali.

D. 242. Car je t'aim de cuer si parfait.

M. 252. Car je vous aim, dame, de cuer si vray.

D. 72. . . laisse pour un autre amer

M. 326. . . laist pour un autre acointier. 
D. 242. Dous amis, que t'ai je meffait? - : fait.

M. 327. . n'a rien meffait $\mid$ Dous amis, que vous m'avez fait.

D. 56. Il n'est biens ne joie qu'il m'aporte.

M. 133. il n'est biens ne joie (ne confort) qui -.

D. 119. cui j'ay donné m'amour.

M. 159. a qui j'ay donné m'amour.

D. 153... que vostre cuer fait en moy son demour: - amour.

M. 184. . qui fait en mon cuer son demour: - amour.

D. 242. Voy la peine, voy le labour.

M. 185. Voy ma peine, voy mon labour.

D. 246. Car en toy sont tuit mi desir.

M. $211 .$. et en qui sont tuit mi desir.

D. 208. . diray a chiere lie.

M. $217 . .$. donner a chiere lie.

D. 56. . . je suis saoule de plourer.

M. 306. .. j'estoie saous de plourer.

D. 72. . pour crealure nee: pensee.

M. 20. .. ne a crealure nee ne gehiray ma pensee.

D. $114 .$. joie et pais et mercy.

M. 316. .. joie, pais et alligement.

D. 187 ... si que cuer, penser, amour, Voloir, espoir et desir.

M. 252. . . m'esperance, Mon cuer, mamour, mon desir, ma plaisance, Tout mon penser.

D. 36. Si n'ay pas corps pour tels fais endurer.

M. 130. . je n'ay pas corps pour tels cops endurer.

Auffallender noch ist die Gleichartigkeit des Stils in den Briefen, wo man sich oft erst an Ueber- und Unterschrift überzeugen mufs, von wem sie geschrieben und an wen sie gerichtet sind. Allerdings muls man bedenken, dafs im Briefstil zu Anfang und Schlufs in den Briefen gewisse Formen und formelhafte Wendungen auch bei uns angewandt werden. Indes ist die Gleichförmigkeit der Form sowohl als des Inhalts bei den 46 Briefen zu grofs, als dafs sie ledigläch aus diesem Umstande zu erklären wäre. Bei einem wirklichen Briefwcchsel könnte man etwas mehr Abwechselung voraussetzien; man vermifst diese aber in Gedanken wie in Ausdrücken. Die Anordnung ist beinahe schematisch. Zu Anfang wird stets mit denselben Wendungen aus vollem Herzen gedankt für die vorige Sendung. Beide können nicht genug ihre Freude ausdrücken, die ihnen die Briefe bereiten und die Nachrichten über den Gesundheitszustand der oder des Geliebten. So erkundigt sich der Absender auch nach dem Befinden des Empfängers und bittet darüber um Nachricht. Vgl. folgende Beispiele: 
D. S. 165. . j'ay receu vos lettres et ce que vous m'avez envoü, de quoy je vous merci tant et de cuer comme je puis plus; et par especial de la bonne diligence que vous avés eue de moy faire savoir vostre bon estat; car c'estoit le plus grant desir que je eusse que de savoir que vous fussies en bon point.

I 19. j'ai receu vos lettres, en queles vous me failes savoir vostre bon estat, dont j'ay moult grant joie plus que de chose qui me puist avenir.

133. j'envoie par devers vous pour savoir vostre bon estat, le quel je desire plus a savoir que nulle riens nee, ne que de creature qui vive: et du mien, s'il vous en plaist a savoir, j'estoie en estat que ...

47. .. je n'eus longtemps a si grant joie comme je eus a l'eure que je les (sc. lettres) receus; pour ce que j'avoie grant desir de savoir nouvelles de vostre bon estat.

Aehnliche Anfänge finden sich bei Machaut, wie folgende:

S. 54. vous me failes savoir vostre bon estat dont je suis moult liès. Et vraiement c'est la plus grant joie que je puisse avoir que d'en oïr bonnes nouvelles.

201. j'ai receu vos letlres es queles vous me faites savoir vostre bon estat, dont j'ay si tresgrant joie que plus ne puis.

262. .. j'envoie par devers vous pour savoir vostre bon eslat, car, par Dieu, c'est une des choses de ce monde que je plus desire que d'en oür bonnes nouvelles et vous veoir aussi. Et du mien, s'il vous plaist a savoir, plaise vous savoir que - nous estions en bon point.

Derartige Eingänge finden sich in Menge. Formelhaft ist auch der Schlufs mit der fast immer wiederkehrenden Wendung: a Dicu, mon dous cuer (cet), qui vous doint joie et honnour de quanque vostre cuers aime, wofür besondere Belegstellen wohl überflüssig sind. Ebenso kommt häufig der Wunsch zum Ausdruck, sich zu sehen, und die Versicherung ewiger Treue, so z. B.:

D. I I5. ne vueilliés penser ne ymaginer que je vous puisse laissier ne oublier.

D. 207. l'amour que j'ay a vous est si grans que nul puet plus estre.

D. 267. ne jour de ma vie ja ne vous oblieray.

M. 113. . . par ycelui dieu qui me fist il ne porroit avenir que je vous oubliasse.

M. I64. . . car par m'ame je ne vous porroie ne vorroie oublier.

M. 61. ... que j'aime le plus et en cui j'ay plus grant fiance.

D. 3 10. moi qui vous aime plus chierement que tous les hommes qui sont aujourd'hui en vie.

M. 201. vous que j'aime plus que tout le monde...

D. 346. . . si dieu m'avait donné un seul souhait en ce monde ge ne souhaideroie riens fors vous veoir.

M. 20. se je avoie en ce monde un seul souhait je souhaideroie que je peüsse mon cuer et mes yeux saouler de vous veoir et ö̈r.

D. 207. . . je pense tant a l'amour qui; est entre vous et moy que par le dieu en qui je croy je $y$ pense plus que en nulle autre chose. 
M. 258. . en l'ame de moy en tout le siecle je n'ay pensed que a vous ne je ne porroie ne saroie amer autre que vous.

D. 344. (j'ay receu vos letlres dont j'ay moult grant joie). Car aprés vous veoir c'estoit la chose du monde que je desiroie le plus.

M. I 3. c'est la plus grant joie - que de oir bonnes nouvelles aprés vous veoir que je desir sur toutes choses dou monde.

Dabei wird gebeten, so oft als möglich zu schreiben, vgl.

D. 58. je vous pri que je oie nouvelles de vous le plus souvent que vous porrés.

M. 342. Si vous supply - que vous le (le bon estat) me vueillez faire savoir le plus souvent que vos pourrez.

Ferner folgen Entschuldigungen, nicht eher, nicht ausführlich genug oder nicht in ganz geziemender W'eise geschrieben zu haben, so z. B.:

D. 280. si vous escri briefment je vous pri qu'il ne vous vueille desplaire.

M. 266. Et si je vous escri trop briefment, pardonnez möi.

D. II4. Je vous pri tant doucement que je puis qu'il ne vous vueil desplaire se je ne vous ay escript.

M. I12. .. je vous prie pour Dieu que vous me vueilliez tenir pour excuse, se je n'ay envoie vers vous .. mais, par m'ame, je ne l'ay peu amender.

D. 345. Et se je vous ay escrit un pou rudement et mal saigement, par m'ame, je ne l'ay peu amender.

M. 54. se je vous ecri plus rudement, nicetement et mal sagement - si le me vueillies pardonner.

Ebenso wird beiderseitig die hohe Befriedigung ausgedrückt, die ihnen die Liebe gewährt, eins fühlt sich durch die Liebe des andern geehrt, und sie suchen sich im Ausdruck ihrer Gefühle zu überbieten.

D. 235. . . quant il me souvient - de l'honneur et dou bien que je trouvay en vous tous li cuers me rejoist.

M. 258. Et se Dieu me doint joie je vous aim tant et poise tant l'onneur el la bonté de vous qu'il ne me puet sembler que vous ayes pareille.

M. 258. Mais ainsi ce que je ne suis mie digne de vous amer me donne trop de pointures.

D. 27. . et si ay tant enquis de vostre estat, que se je estoie cent fois meilleurs de toutes bontés que je ne suis si suis je certaine que vous estes bien souffisans d'avoir meilleur que je ne suis.

M. 19. .. se je estoie li plus vaillans - et vesquisse cent mille ans, je ne porroie mi desservir la menre partie des biens que vous me faites. Et - vous dites que vous prenes grant plaisance en ce que je vous envoie; je doy prenre cent mille fois plus grant plaisance en ce que vous m'envoiez.

D. 47. Et se vous prenés grant plaisir a veoir et a tenir ce que je vous ay envoik, je cuide certainement que je le pren plus grant a veoir ce que vous m'avez envoie. 
Der Bau der Sätze ist durch Häufung gleichwertiger Satzteile und synonymer Ausdrücke, durch Anaphern u. dergl. übereinstimmend, sowie auch gewisse Wendungen und Uebergänge an einander erinnern. Solche gleichwertige Satzteile finden sich in allen Briefen, z. B. bei Machaut:

19. je prens joie, plaisance et douce nourriture.

2I. je vous ameray et obeïray, doubteray, serviray tant com ie vivray, et de cuer loiaument garderay et celeray.

4I. .. ne pourroient penser, imaginer ne considerer.

53. que je pren en penser, en parler et en escrire.

54. souhaidier ne desirer. je pren joie et confort et vrai esperance.

I13. met m'ame, mon cuer, ma vie et quanque j'ay en vostre ordenance.

189. ne tristesse ne dolour; rendu joie et santé.

191. je vif en joie et en revel.

258. escriray, diray ne commanderay. ma sante.

265. ma mort et ma vie, mon deduit et ma joie, ma doleur et

Von dergleichen Wendungen seien aus den Briefen der Dame folgende erwähnt:

48. le bien et l'onneur.

62. je ne pren plaisance, comfort ne esbatement que en vous.

I15. .. penser ne ymaginer que je vous puisse laissier ne oublier. 165. Le bien, l'onneur et la douceur.

3 Io. n'en dis n'en fais n'en pensee. bien ne joie, confort et joie.

312. en qui j'ay mis cuer, pensee et amour.

Ferner erinnern an einander folgende Wendungen:

D. 62. a vous que j'aim plus que moi.

M. 100. a vous que j'aim trop mieus que mi.

D. 249. Si vous prie si chier come vous avez - l'amour de moi que ...

M. 258. Mais je vous pry si cher que vous m'amez que...

M. 20. et vous jure et promet par ma foy que ...

D. 168. je vous jur et promet par ma foy que...

D. 193 und öfter. que je porroie ne vorroie.

M. I64 und öfter. je ne vous vorroie ne porroie.

D. 28I. je suis la ou vous savez en tres bon point, la mercy Nosire Seigneur qui ce vous ottroit.

M. 278. j'estoie en bonne santé de corps, la mercy Nostre Seigneur qui ce vous ottroit.

D. 368. .. come vous amez mon bien, ma pais, ma joie et ma vie.

M. 362. si vous amés mon bien, ma pais et ma joie. 
D. 312. Si vous prie et supply si humblement et si chierement come je puis.

M. 362. Si vous pry si tres chierement et si humblement come je puis.

D. 62. je vous pri sur toute l'amour que vous avez a mi que...

M. 52. je vous pri pour Dieu et sur toute l'amour que vous avez a moi que...

Sodann ist beiden eigentümlich, von demselben Verbum verschiedene Zeiten neben einander des Nachdrucks halber anzuwenden, so z. B. elle m'a amendé et amende, me donnent et ont donné, sui et seray toute ma vie, j'ay et aray, il n'i a que bien ne n'ara ja u. dergl.

Dazu wenden beide gern und häufig Beteuerungen an.

Auffällig ist auch, dals in den Briefen der Dame, die doch ein Bekanntwerden ihrer Beziehungen wünscht, ebenso sorgfältig wie bei ihm Angaben von Personen oder Orten vermieden sind. Sonderbar ist das Verfahren, in den Briefen allgemeine Redensarten zu machen und dann, wenn etwas Bestimmtes und Wesentliches für Ort und Zeit kommt, zu schreiben, das werde der Ueberbringer des Briefes mitteilen, die Hauptsache also, die oft geheim bleiben soll, dem häufig als valet bezeichneten Boten mündlich anzuvertrauen, diesen also mit dem wesentlichen Inhalt des versiegelten Briefes bekannt $z \mathbf{u}$ machen. Man bekommt hier beim Lesen das Gefühl, als mache der Dichter deshalb Phrasen und dunkle Andeutungen, weil er sich etwas Klares und Bestimmtes beim Schreiben der Briefe selbst nicht vorstellt.

Der Stil der Briefe ist somit sehr auffällig; die Aehnlichkeit der Form, das Andeutende des Inhalts legen den Gedanken nahe, dafs der ganze Briefwechsel blofs erfunden ist. Natürlich kann man hieraus allein einen bestimmten Schlufs nicht ziehen, wenn nicht noch andere wesentliche Momente hinzukommen.

\section{Sachliche Bemerkungen.}

In sachlicher Hinsicht findet man manche auffälligen, zum Teil sich widersprechenden Stellen.

S. 36: Machaut sagt, er habe vier Gedichte während seiner Krankheit gedichtet; er teilt sie uns mit. Von ihnen verdient das dritte und das vierte erwähnt zu werden.

In Gedicht 3 spricht er davon, dafs er keine Sorgen und Schmerzen habe, dafs er geheilt sei durch seine Dame. Das widerspricht sowohl seinem physischen als geistigen Zustand nach den, was er kurz vorher erzählt hat. Denn er ist in seine Krankheit zurückgefallen aus Sehnsucht nach ihr, weil er nichts wieder von ihr gehört hat. Vgl. S. 24: 


\section{Si devins merencolieus;}

Car vraiement j'estoie en double

De perdre m'esperance toute,

Et s'estoie flebes asse's

Et de maladie lassís ...

Hier ist also sein Zustand ganz anders als er ihn in Gedicht 3 darstellt.

Das 4. Gedicht, eine chanson baladee, behandelt seine Gedanken darüber, wie er sich beim ersten Zusammentreffen mit ihr verhalten wird.

Certains sui que pris seray

Si fort que je ne saray

$A$ li parler

Et que sans froit trambleray

Et sans chalour sueray

Et souspirer

Me faudra et resoper

Mes souspirs pour moi celer.

La ne saray

Mot sonner ...

Auf S. 80 schildert er nun diese Zusammenkunft:

$$
\text { ... je ne savoie }
$$

Parler a li ne ou j'estoie.

$E t$ si sentoie une froidure

Entremellee d'une ardure

Qui faisait fremir et suer

Mon corps et ma colour muer.

La parole me trembloit

Et tous li corps, ce me sembloit.

Die Aehnlichkeit der beiden Stellen liegt auf der Hand. Der Dichter muls sich zum mindesten sehr gut gekannt haben, wenn er so genau schon vorher zu schildern weifs, wie er sich verhalten wird. Die beiden Gedichte haben sonach manches Auffällige, das eine widerspricht der Situation, in der es gedichtet sein soll, das andere erregt Zweifel wegen der Aehnlichkeit seines Inhalts mit dem später Erzählten.

Folgende Verse auf S. I I I sind psychologisch unwahrscheinlich: S'avoit en mon cuer

bis Comment maintenir me devoie.

Man mufs bedenken, dafs der Dichter nur acht Tage ohne die Dame ist und dafs diese ihn in der Zwischenzeit noch besucht. Innerhalb dieser Zeit von nicht ganz acht Tagen werden vier Briefe (1 1.-14.) gewechselt. So ist der Anfang von Brief 1 I eine blolse Phrase: me vueilliez tenir pour excusé, se je n'ay envoié vers vous puis que vous partistes de moy. Ebenso entschuldigt sich in Brief 12 
die Dame, dafs sie noch nicht geschrieben hat, m. E. ganz ohne Grund.

S. I63. Zu der Angabe, dafs Brief 19 am Tage der Abreise des Dichters geschrieben sei, steht im Widerspruch der Stil des Briefs und der ganze psychologische Zusammenhang. Ebenso ist es mit Brief 20, S. 165, den wir dem Stil nach nicht am andern Tage nach der Abreise geschrieben denken können: il ne fu puis jours a celle droile heure par especial que il ne me souvenist de vous. Damit kann doch nicht nur ein einziger Tag gemeint sein?

S. 182. . pour amende tauxee par li et par ses gens, de ce que en ce livre ne avoie riens fait d'especial chose qui feist a conter pour li, je feisse un lay appelle Lay d'Esperance. Diese Stelle könnte, wenn eine, zeigen, dafs alles vom Dichter erfunden ist. Denn nach der Stelle, die der betreffende Brief 21 einnimmt, und nach der Zeit, in der er den Angaben zufolge geschrieben ist, ist das Buch überhaupt noch nicht angefangen, da der Brief bald nach des Dichters Heimkehr geschrieben sein mufs, er aber erst über einen Monat nach seiner Trennung von der Dame, wie oben gezeigt ist, mit der Arbeit beginnt. Es ist unmöglich, in Brief 21 schon von dem Buche als einem zum Teil fertig vorliegenden Ganzen, wie es geschieht, zu sprechen. Man sieht indessen, dafs von dem Werk schon ein Teil fertig ist, den der Dichter überblickt und worin er noch nichts von Esperance gedichtet hat, als der Brief geschrieben wird. In dem Briefe sind also unwillkürlich des Dichters Gedanken bei der Komposition zum Ausdruck gebracht, nicht aber die, welche er dem Gang der Ereignisse nach haben würde, wenn der Briefwechsel echt wäre.

S. 234. Die Dame schreibt, dafs sie in der Nacht zum hl. Kreuz (am 8. September) einen Traum gehabt hat und teilt ihn dem Dichter in dem Briefe 29 mit. Dieser antwortet: sachiez certainement que je songay environ la Sainte Crois und erzählt seinerseits den Traum, den er um dieselbe Zeit gehabt hat. Das wäre also auch etwa am 8. September. Sodann aber schreibt er S. 233, dars am selben Morgen, nachdem er den Traum gehabt hat, ein Bote von der Dame mit dem betr. Brief (29) kommt; der ist aber vom 17. September datiert. Er mü/ste danach erst nach dem 17. seinen Traum gehabt haben. So stimmen zum mindesten die beiden Daten nicht.

S. 243. In der Complainte der Dame ist eine Stelle auffallend, die trotz ihrer geringen Bedeutung für die Erzählung geeignet ist, bedeutenden $Z_{w}$ weifel an der Echtheit der Complainte als eines Werkes der Dame und dann an der des ganzen Briefwechsels überhaupt hervorzurufen. Die Dame erwähnt nämlich hier, dals der Dichter sie mit Semiramis verglichen habe. Das hat er in 
dem Werke allerdings vorher gethan; aber es ist nicht ersichtlich, wie die Dame davon wissen kann. Denn in den Briefen steht davon nichts, auch kann ihr das Buch noch nicht soweit vorgelegen haben, da es noch nicht sehr lange begonnen ist und er nach S. 202 täglich 100 Verse macht. Direkt vorher steht der Vergleich mit Semiramis. Dafs er das Buch der Dame noch nicht geschickt hat, zeigt Brief 34 und 35, die erst nach der Complainte geschrieben sind. Woher weirs also die Dame, die das Buch noch nicht gesehen und von dem Dichter über diesen Punkt keine Mitteilungen erhalten hat - abgesehen davon dals das Werk da schon sehr weit vorgeschritten wäre Vergleich angewandt hat? Es scheint mir hier eine Unachtsamkeit des Dichters vorzuliegen, die er dann bei der an und für sich geringen Wichtigkeit der Sache nicht bemerkt hat. $\mathrm{Er}$ hat die Complainte wohl selbst gedichtet.

S. 308. Dafs der Dichter Seite für Seite weiter gearbeitet hat, ohne das Vorhergehende $\mathrm{zu}$ vergleichen und entsprechend $\mathrm{zu}$ ändern, sieht man daraus, dafs er S. 308, wo er das Bild der Dame herabnimmt und in die Truhe legt, sagt:

\section{La est encore et $y$ sera \\ $N$ 'a piece mais n'en partira.}

Später erzählt er aber, dafs er das Bild wieder hervorholt und an dem alten Platze aufhängt.

Ueber die Abfassung des Buchs sind in den letzten Briefen verschiedene Angaben gemacht. Von Br. 39 ausgehend, sehen wir, dafs der Dichter das bisher Fertige der Dame gesandt hat. Der Verkehr ist dann abgebrochen. Wie hat er da das Buch wieder erhalten, das sie in Br. 43 noch einmal haben will? - In Br. 42 schreibt er, wegen der Aeufserungen des riche ami habe er puis Pasques nichts an dem Buche gearbeitet, wolle auch nicht weiter arbeiten, puisque matere me fault, und doch sendet er ihr zugleich das, was er depuis de vostre live gethan hat. In $\mathrm{Br} .45$ ist die baldige Vollendung in Aussicht gestellt, nachdem: j'ay esle lonc temps que je niy ay riens fait.

Unwichtigere Stellen mit Widersprüchen übergehe ich.

Die Zeitangaben im allgemeinen.

In den Zeitangaben finden wir viele Widersprüche, weniger in dem ersten Teile des Buches, als in der zweiten Hälfte. Besonders in den Daten der spätern Briefe sind viele Ungereimtheiten, die sich durch Umstellung einzelner Briefe nicht alle beseitigen lassen. Diese Widersprüche sind zum Teil sehr auffallend. Wir wollen versuchen, durch Aenderungen bzw. Umstellungen sie zu beseitigen und so Klarheit in den Gang der Handlung zu bringen. P. Paris 
hilft sich hierbei damit, dafs er sagt, was nicht zusammenstimme und falsch sei, habe der Dichter mit Absicht so gemacht, damit man schwerer hinter sein Geheimnis komme. Das ist allerdings ein bequemes Auskunftsmittel; an vielen Stellen ist es aber nicht angebracht, eine absichtliche Täuschung anzunehmen, da sie gar keinen Zweck hätte. Gelingt es nun weder die Widersprüche zu beseitigen noch Gründe dafür zu finden, so kann man dagegen durch Nachweisung solcher auf indirektem Wege das Nichtwirkliche des Erzählten nachweisen. An und für sich können ja in jedem Geschichtswerke solche sich widersprechende Angaben vorkommen; doch kann es sich dabei nur um Versehen und Unwesentliches handeln, oder der Geschichtsschreiber stützt sich auf falsche Quellenangaben, oder er hat, wenn er eigene Erlebnisse schildert, infolge davon, dafs sie lange vergangen sind, manches vergessen und kann den Zusammenhang nicht mehr klar konstruieren, sieht vielleicht auch manches in anderm Lichte. Das liegt aber bei unserm Werke nicht vor, da nach des Verfassers eigenen Angaben das Buch immer in unmittelbarem Zusammenhang mit den Ereignissen geschrieben wird, die geschilderten Vorgänge also noch in lebhafter Erinnerung sind. Widersprüche sind also hier nicht auf mangelhaftes Gedächtnis, auch nicht auf schlechte Ueberlieferung aus dem Munde anderer zurückzuführen, sondern auf falsche Kombinationen und Kompositionsfehler. Bei frei erdichtetem Stoffe ist es ja allerdings eher möglich, dals der Autor bei Zeit- und andern Angaben vergifst, was er vorher angab; natürlich tritt ihm das nicht ins Bewulstsein, und so unterlälst er den sonst möglichen Vergleich mit dem früher Geschriebenen, zumal wenn die Arbeit rasch gefördert werden soll. Auch geht es leicht an, dafs er auf Augenblicke den Standpunkt der Erzählung vergifst, wie das auch bei den Briefen in Bezug auf die Zeit des Absendens möglich ist, und dals er von seinem Stand- und Zeitpunkte bei der Abfassung des Buches ausgeht, wie das 2. B. in Brief $2 \mathrm{I}$ der Fall ist.

lch stelle zunächst die Zeitangaben in der Folge des Textes zusammen, um sie dann zu vergleichen und die Richtigkeit einzelner genauer zu untersuchen, besonders auch auf die Daten der Briefe einzugehen. Einige Wiederholungen lassen sich hierbei allerdings kaum vermeiden. Man vergleiche hierzu den Inhalt.

Ausgehend von dem oben festgesetzten Anfangstermin der Abfassung des Buches, Juli $\mathbf{1}_{3}$ 63, kommen wir bei Beginn der Erzählung in den Spätsommer des Jahres I 362. S. 2:

Il n'a pas un an que j'estoie

En un lieu ou je m'esbatoie.

Si m'estoie couchiés en l'ombre

Par quoy la chaleur du soleil

Ne me grevast n'au corps n'a l'ueil. 
Die Jahreszeit ist also noch sehr schön, es ist warmes Wetter, wir können annehmen August oder September. Der Freund, welcher die erste Nachricht von der Dame und das Rondel gebracht hat, reist bald wieder ab, um der Dame des Dichters Antwort $\mathrm{zu}$ bringen. Eine $Z$ wischenzeit ist nicht angegeben bis zur Ankunft des Boten mit dem Briefe: Ainsi com j'estoie la S. 13 ist alles, was gesagt ist. Doch muls einige Zeit vergangen sein. Der Dichter giebt dem Boten Brief 2. Dieser erklärt ihm, S. 23,

qu'il ne pooit si tost aler

Vers ma dame, n'a li parler.

Der Liebende bleibt zwei Monate ohne Nachricht, also Oktober und November:

Je fui deux mois tous entiers

Qu'il ne fu voie ne sentiers,

Homme, femme ne creature,

Qui de ma douce dame pure

Me deïst aucune nouvelle.

Der Winter ist streng. S. 24:

Et si estoit trop grans l'yvers

Plains de gelee et pluvieus.

Nach Empfang des zweiten Briefes schreibt die Dame sofort wieder, S. 27:

\section{Car en l'eure me volt rescrire}

Ces lettres que cy orrés lire.

Machaut seinerseits antwortet sofort mit Br. 4. Diesen hat sie le juedi devant Noël erhalten (S. 47). Brief 3 und 4 sind also im Dezember geschrieben.

Von der Zeit nach Weihnacht bis zum Frühling wird nichts berichtet; der Dichter wird merkwürdigerweise nicht wieder ernstlich krank, als Nachricht von ihr nicht gleich eintrifft. In $\mathrm{Br} .3$ (S. 28) hat sie ihm mitgeteilt: vueillies savoir que je ne me partiray point de la ou je suis avant Pasques. Sie ist noch in derselben Stadt, die sie bei Beginn des Winters aufgesucht hat, wie wir oben sahen vermutlich in Paris.

Der Frühling vertreibt nun den Winter. S. 42: $L i$ printemps vint biaus et jolis. Der April ist herangekommen, S. 43: $C e$ fu droit au mois d'avril. Auf S. 46 wird die Ankunft des Boten, der Brief 5 bringt, mitgeteilt. Dieser Bote kehrt nach S. 47 nicht sofort zur Dame zurück, sondern geht eine Woche nach Lothringen:

Je suis de la conte de Fois

Et m'en vois tout en droit en Lorraine:

Si revenray l'autre semaine.

Er kann also, wenn er Brief 6 auf der Rückreise mitnimmt, kaum vor Mitte April wieder in Paris bei der Dame sein. Der Dichter schreibt nun in Brief 7 (S. 53): Se je puis par nulle voie, je vous 
verray environ ceste pasque. Das Osterfest mülste demnach noch nicht vorbei sein. Nach den Ostertabellen ist aber das Fest im Jahre 1363 bereits am 2. April, also noch vor der Ankunft des Boten. Der Widerspruch liegt auf der Hand: in einem nach Ostern geschriebenen Briefe wird das Osterfest als künftig bezeichnet. Will man hier eine absichtliche Täuschung von seiten des Dichters annehmen? Doch wohl schwerlich; denn diese könnte dann doch erst später ausgeführt sein, nachdem die Dame ihm den Brief zurückgegeben hat, da sie sonst selbst nicht wissen würde, welche Zeit gemeint ist, und wenn das, so wäre der Brief nicht in seiner ursprünglichen, wahren Form aufgenommen, was der Dichter doch gerade will. Aufserdem fällt der Widerspruch beim Lesen gar nicht auf, erst bei genauer Betrachtung der Zeitangaben und des wirklichen Datums. Ich nehme an, dafs dem Dichter das entgangen und nicht mit Absicht geschrieben ist. Aber auch ohne auf das wirkliche Datum $\mathrm{zu}$ achten, findet man, wenn man die Zeitangaben unter sich vergieicht, Widersprüche heraus. S. 68 verspricht er der Dame, zu Pfingsten zu kommen. Berechnet man nun die Zeit, die von $\mathrm{Br} .5$ bis zu seiner Reise vergeht, so kommen wir in den Anfang des Monat Mai, also in eine Zeit, wo Pfingsten noch nicht fallen kann. Die Dame erhält nämlich Br. 6 Mitte April. Die Zwischenzeit $\mathrm{zwischen} \mathrm{Br}$. 6-10 ist nicht angegeben. Da die Entfernung zwischen Reims und Paris doch sicher vier Tagereisen betrug, wenn nicht mehr, so müssen wir zur Beförderung der Briefe immer vier Tage annehmen. Die Antwort ist jedenfalls auch nicht immer am selben Tage abgeschickt, vgl. Br. 9 und 10 , wo von einer längern $Z$ wischenzeit geredet wird. So kommt eine Zeit von mehr als 20 Tagen heraus. Seine Reise könnte er vor dem 5.- - 0 . Mai hiernach nicht antreten. Pfingsten ist danach allerdings nicht mehr fern. Wenn wir aber die folgenden Zeitangaben des Buches zurückrechnen von dem Termin, den wir immer als Ausgangspunkt für die Rechnung nehmen können, dem Lendit von St. Denis, I 2. Juni, so bekommen wir einen frühern Tag; er mürste da noch im April reisen. Allerdings sind die Angaben betreffs seiner neuvaine ziemlich unklar. Auch P. Paris scheint sich nicht ganz damit zurechtgefunden $z u$ haben. In Brief 10 teilt M. der Dame mit, dafs er zu Pfingsten kommen werde. S. 66, wo er le printemps vit bel et joli, beschliefst er die Reise, auf S. 70 erzählt er, dafs er sie antritt. Wie lange Zeit er dazu gebraucht, ist nicht angegeben. In seinem Wallfahrtsort, nahe dem Wohnsitz des Fräuleins, will er zuerst neun Tage bleiben; doch verlängert sich sein Aufenthalt. Die Stelle lautet:

Que j'y feïsse ma nuefvaine;
Mais j'y fui pres d'une quinzaine
Pour un accident qui me vint.
Car de la partir me convint
Au commendement d'un seigneur,




\section{Qu'en France n'a point de greigneur \\ Fors un. \\ Mais ce ne me desploisoit mie, \\ Car jaloie veÿr m'amie.}

Mit diesem Herrn ist der Dauphin, Herzog der Normandie, gemeint, der sich damals in der Stadt Crecy aufhielt, wie aus S. 136 hervorgeht:

\section{Je receu ceste letre cy \\ Droit en la ville de Crecy. \\ La fu le duc de Normandie, \\ Mon droit Seigneur.}

Obige Stelle besagt also, dafs der Dauphin ihn vierzehn Tage nachher zu sich entboten hat. Da dieser nun in der Nähe weilt, beschliefst der Dichter, nicht erst nach Hause zurückzukehren, sondern an seinem jetzigen Aufenthaltsorte zu bleiben, bis er zum Herzog gehe. Der längere Aufenthalt ist ihm nicht unlieb, da er so besser Gelegenheit hat, seine Freundin zu sehen. Ob in der quinzaine nun die neuvaine inbegriffen ist oder nicht, ist nicht klar ausgedrückt. Die spätern Angaben zeigen aber, dafs er länger dableibt als vierzehn Tage im ganzen. P. Paris äufsert in diesem Punkte zwei verschiedene Ansichten; er schreibt: obligé d'aller rejoindre, à quinze jours de la, le duc .. il n'étoit pas retourné à Reims aussitôt sa neuvaine accomplie. Damit meint er doch, dafs der Dichter aufser den neun noch vierzehn Tage blieb, rechnet auch unter dem Text so. In der Anmerkung über diese Stelle am Ende des Buches schreibt er aber, S. 389: Il devoit au mandement du prince la facilité de rester à portée de voir sa dame cinq ou six jours de plus. Er weils anscheinend die Zeitbestimmungen auch nicht recht in Einklang zu bringen. Der Dichter vollendet seine neuvaine nicht; denn die Dame schreibt ihm, er solle eher zu ihr kommen:

\section{Ma dame m'escript doucement \\ Qu'elle desiroit durement \\ Que je par devers li alaisse, \\ Et que ma neufvaine laissasse.}

Demzufolge macht sich der Dichter sofort nach dem zwei Stunden entfernten Ort des Mädchens auf. Wie lange er schon an seinem Wallfahrtsorte war, schreibt er nicht. P. Paris nimmt sieben Tage an, ohne einen bestimmten Grund dafür anzugeben. Nach seinem Gelübde, dafs er jeden Tag ein Gedicht zu Ehren der Dame machen will, ist er nur drei Tage hier, da drei Gedichte hier angeführt werden, zu jedem allerdings die Antwort der Dame. Bei ihr bleibt er acht Tage, S. 98:

La demouray huil jours entiers.

Hierauf kehrt er zur Wallfahrtskirche zurück:

$$
\text { m'en alay bouler en cage }
$$

Pour faire mon pelerinage. 
Er beginnt seine neuvaine, die nicht unterbrochen werden durfte, von neuem, S. 108:

$$
L a \text {, fait neuf jours ma demeure ay. }
$$

Von hier schreibt er Brief I I, dem die Antwort bald folgt. Br. 13 ist wieder sofort geschrieben. Die Zeitangaben in $\mathrm{Br} .12$, den die Dame schreibt, sind nicht wesentlich, S. 114: J'ay bien veu que vosire nuefvaine ne sera ce prochain dimenche assevie; et celui jour, il convient partir, ma suer et moy, pour aler a quatre lieues long; et suis certeinne qu'il sera avant le lundi le soir ou le mardi ou matin que nous retournions. Merkwürdig ist die Textänderung von P. Paris in seiner Ausgabe: ne sera assevie; die drei Handschriften haben das ne nicht. Fin Grund zu der Aenderung ist nicht einzusehen. Am selben Tag, wo sie abreist, kommt der Liebende an ihren Ort. Er hat sie vorher in Br. 13 nochmals gebeten, dazubleiben, da er nicht lange mehr bleiben kann; denn Monseigneur m'a mandé par ses letlres que, ma neuvaine faite, je voise par divers lui. Hier betont er, dals er nach Ablauf der neuvaine kommen soll. Ob er neue let tres bekommen hat, kann man nicht wissen; infolge dessen hilft diese Stelle nicht, die obige Schwierigkeit betreffs der neun und vierzehn Tage zu beseitigen. Die Dame ist aber gezwungen, zu reisen, kann seinen Bitten nicht nachgeben (Br. 14).

Nachdem er nun an den Ort der Geliebten gekommen ist, bleibt er zwei bis drei Tage in Traurigkeit allein. Dann kommt sie zurück. Er wagt zuerst nicht, zu ihr zu schicken, bekommt auch keine Botschaft: $S i$ fui longuement en ce point. Endlich schickt er Br. 15 (S. I 22): vous porrés savoir que je vous ay alendu trois jours en tel estat comme Dieus scet. Er hat also wieder drei Tage gewartet, sechs Tage im ganzen in diesem Orte. Die Freundin entbietet ihn nun zu sich; er bleibt hier nach S. 128 trois jours et trots nuis. Der Aufenthalt beträgt hier nun neun Tage, dazu kommt die neuvaine, neun Tage, so dals wir, abgesehen von den acht Tagen vorher, die quinzaine schon überschritten haben. Selbst abgesehen von der netwaine kommen mehr als fünfzehn Tage heraus, nimmt man die drei bzw. sieben lage seines Aufenthalts in dem Wallfahrtsort hinzu, die er vor dem Zusammentreffen mit der Dame dort verbrachte. Nach unserer Rechnung bekommen wir, einschljefslich neuvaìe, 29, nach der von P. Paris 33 Tage heraus. Ein ganzer Monat ist somit vergangen seit seinem Aufbruch von Reins. Nun geht er zum Herzog der Normandie, schreibt Br. 16, ehe er zu Rofs stieigt. Bei seinem Herrn bleibt er beinahe vierzehn Tage, S. I32: La demouray pres de quinsaine. Jede Woche schickt er mindestens einmal an seine Dame. In Brief 17 stellt er ihr in Aussicht, dafs er noch auf drei bis vier Tage zu ihr kommen werde, S. 134: je demourray trois jours ou quatre la ou vous estes. Die Dame antwortet sofort: me rescript par mon message et sans attendre, Brief 18 . So nimmt er endlich Urlaub vom Herzog, S. 139: 
J'alay congit prendre;

Mais Monseigneur me fist attendre

Contre mon gre, trois jours ou quatre.

Et puis me parti.

Er reist nun wieder an den Ort der Dame. Der Erzählung nach zu schliefsen unternehmen sie die Pilgerfahrt nach St. Denis gleich am andern Tage nach seiner Ankunft, S. 143:

Le jour aprés nous en alames, Son pelerinage paiames.

Ce fu droit le jour que l'en dit

La beneisson du Lendit.

Das ist der 12. Juni, das erste feste Datum, das wir in dem Buche bekommen. Rechnen wir von diesem Zeitpunkte zurück, so bekommen wir folgende Daten:

Am I2. Juni ist er in St. Denis.

" I1. " geht er zur Dame vom Herzog.

Bei diesem ist er vierzehn Tage, etwa vom 27. Mai bis I1. Juni. Nach der neuvaine ist er neun Tage am Orte der Dame:

18. Mai bis 27. Mai. Die neuvaine ist dann

9. " " 18. "

Acht Tage bleibt er nach unterbrochener neuvaine zuerst bei der Dame: I. Mai bis 9. Mai. Mindestens drei Tage ist er vorher am Wallfahrtsort, 27.-30. April. Sonach hat er die Reise noch im April angetreten. Pfingsten fiel aber 1363 auf den 22. Mai.

Nach der andern Rechnung beginnt die Reise Anfang Mai. Somit stimmen diese Zeitangaben mit dem wirklichen Datum nicht überein, was man bei einer historischen Erzählung doch voraussetzen sollte. Nehmen wir hinzu, dafs beinahe ein Monat zwischen der Absendung von Brief 5 und des Dichters Abreise vergangen ist, so stimmt auch der Vers, dafs er Br. 5 im April erhielt, kaum. Die Angaben des Dichters widersprechen sich somit, so dals wir die richtige Zeit nicht genau feststellen können. -

Die Wallfahrt nach St. Denis dauert nur einen Tag, dann kehren die Liebenden an den bisherigen Aufenthaltsort zurück. Der Dichter bleibt bei der Dame noch sieben Tage, S. I5 I:
La demouray sept jours en route, A grant deduit, moy et ma route.
Finablement li termes vint
Que de li partir me convint.

Die Abreise mülste sonach am 20. Juni erfolgt sein. Der Dichter reitet zufolge S. $\mathrm{I}_{3}$ den ganzen Vormittag bis zum Mittagessen. An demselben Tage schreibt er Brief 19 und schickt ihn durch 
einen Boten an die Dame. Der Bote hat also eine halbe Tagereise wieder zurückzulegen. Die Dame erhält den Brief noch am Abend oder am nächsten Tage, schreibt sofort wieder, am 2 I. Juni, S. 164:

\section{elle ne fu perilleuse \\ De rescrire ne mal songneuse, Ains me rescript par le message.}

In dem Briefe sind aber verschiedene auffällige Stellen, wie schon oben kurz berührt wurde:

J'ai receu vos lettres et ce que vous m'avez envoié. Et ay eu plus de bien et de joie au jour et a l'eure que je receus vos lettres que je n'avoie eu puis que vous partistes.

Weiter en verile il ne fu puis jours a celle droite heure par especial que il ne me souvenist.

$S i$ n'os onques mais deux si bons jours a mon grk.

Danach sieht es allerdings nicht so aus, als ob die Dame einen Tag nach der Abreise schon wieder geschrieben hat. Es wird ja ausdrücklich von mehr als zwei Tagen gesprochen. Sonst wären die Stellen ganz sinnlos. Der Dichter erwartet nun den Boten wieder an dem Orte, wo er diniert hat, und empfängt da ihre Antwort. Nach obigen Stellen müfste er mehrere Tage hier bleiben, was aber ganz unwahrscheinlich ist. Die betr. Stelle S. 166 lautet

\section{Quant j'ö̈ sa rescription... \\ Si m'en alay jolis et gais}

Auf Schuld des Boten kann man es auch nicht schieben, dals die Dame den Brief vielleicht viel später erhalten hat, und dals dadurch obige Stellen zu erklären sind. Denn der Bote weils, dafs sein Herr auf Antwort wartet. Der Widerspruch läfst sich kaum lösen; aufserdem erzählt der Dichter nichts von einem längern Aufenthalt an dem betreffenden Ort. Es ist zu vermuten, dals der Dichter eine Unaufmerksamkeit begangen und nicht sorgfältig komponiert hat.

Wie lange überhaupt die Reise dauert, bis er wieder in Reims ankommt (S. I 7 I), ist nicht gesagt. Eine Woche können wir für die Reise wohl annehmen, bedenkt man den Weg und einen kürzern Aufenthalt unterwegs. Anfang Juli ist er sicher wieder in Reims. Brief 2I-27 folgen anscheinend rasch auf einander. Vgl. folgende Stellen:

$\mathrm{Zu} \mathrm{22,} \mathrm{ma} \mathrm{dame} \mathrm{ne} \mathrm{fist} \mathrm{pas} \mathrm{mon} \mathrm{message} \mathrm{attendre;} \mathrm{ains} \mathrm{le} \mathrm{delivra}$ sans attendre.

S. I 84, nach der Schilderung seines Zustandes ist zwischen Brief 22 und 23 einige Zeit zu denken.

S. I 86, zu Brief 24, Lors ma dame de rescrire ne fu pas lente.

S. 189, Br. 25 Si que sans faire long detri

Ceste lettre ci li escri.

Eine Zwischenzeit zwischen 25 und 27 ist nicht angegeben. Br. 27 ist nach dem diesem Briefe zum ersten Male beigefügten Datum 
am 8. August geschrieben. Die Briefe $2 \mathrm{I}-27$ sind also alle im Juli und Anfang August geschrieben. Von jetzt an ist nach dem vom Dichter in Brief 27 ausgedrückten Wunsche, die Briefe zu datieren, ohne den Ort zu nennen, stets das Datum hinzugefügt; scheinbar erleichtert uns das die Feststellung der Zeit, in Wirklichkeit aber nicht.

Die Dame erwidert in Brief 28 le diemenche devant la mie aoust. Sie schreibt darin, der Dichter solle an den bestimmten Ort kommen, wo sie zu sein gedenkt dedens les octaves de la mi aoust; car nous devons partir ce lundi prochain venant, pour $y$ aler, par double de la mortalite. Sobald sie da ist, will sie es ihm mitteilen.

Vorher verbietet sie ihm zu schreiben, ehe er Nachricht hat. Der Dichter bleibt zwei Monate ohne.Botschaft, S. 2 I 2 :

\section{Et ce fu deux mois tous entiers \\ Et aveuc ce j'entrai en tiers, Qu'onques de li n'ö̈ nouvelle.}

221. Il ha pres de neuf semaines Que de li nouvelles certaines $N$ 'oy.

Nach diesen beiden, in allen drei Handschriften übereinstimmenden Angaben müssen wir annehmen, dafs er bis Mitte Oktober ohne Nachricht bleibt. Die Daten der folgenden Briefe sind aber dann alle falsch. Denn trotz dieser zwei Monate schreibt die Dame Brief 29 am 17. September, den er am 28. September beantwortet. Das Datum von Brief 29-33 stimmt also mit obigen Stellen nicht überein. Auch die Angaben in Brief 29 selbst passen nicht zu dem Datum des Briefes. S. 233 schreibt die Dame

1. Je suis ou vous savez, des le vingtieme jour d'aust.

2. nous partismes environ dix-sept jours apres que nous fusmes la venus pour aler en Brie.

3. ... avons la demouré quinze jours entiers.

Rechnen wir das zusammen, so bekommen wir den 21 . September. Dabei ist die Reise nicht einmal eingerechnet. Der Brief mufs demnach nach dem 21 . September geschrieben sein, da er Thatsachen, die bis zu ihm reichen, enthält. Erhalten hat ihn Machaut, wie er S. 239 schreibt, am 28. September: j'ay receu vos lettres la vigile St. Michiel. Wie das Datum zu ändern ist, werden wir später sehen. Brief 31 und 32 scheinen sehr bald darauf zu folgen. Der Inhalt von 32 palst zu dem von 31 und 33, das Datum ist der 5. Mai, natürlich falsch. Von nun an werden die Daten vielfach widersprechend und ungenau. Es möge daher hier eine Zusammenstellung von ihnen folgen, von Brief 27 an, wo das erste Datum steht, bis zum letzten Briefe 46.

Brief 27 Absender M. (Machaut) geschrieben 8. August,

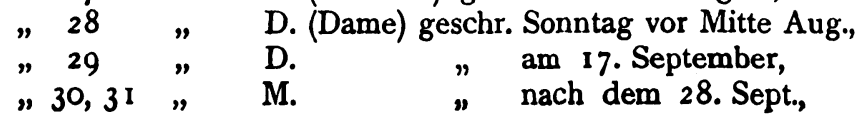




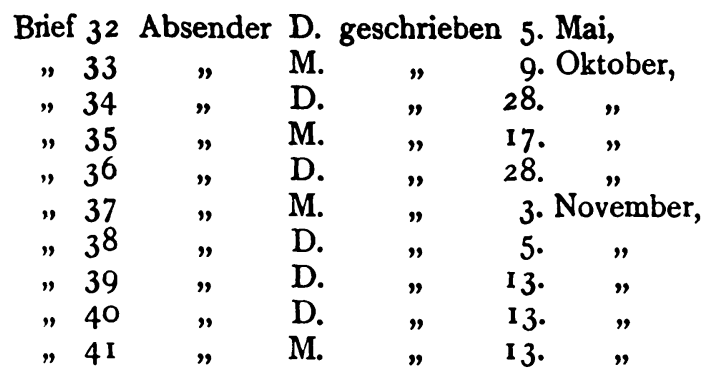

Diese Briefe würden ins Jahr 1363 gehören.

I 364. Brief 42 Absender M. Datum I6. Juni,

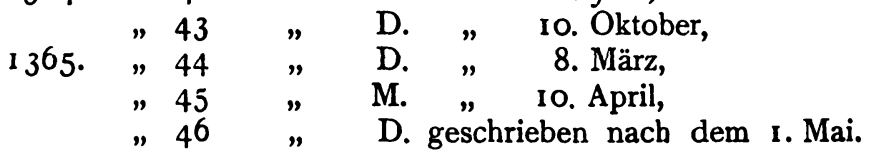

Betrachten wir nun weiter die Briefe nach der Reihenfolge in der Erzählung und im Zusammenhang mit den übrigen Zeitangaben. Brief 34 ist dem Datum nach von der Dame am 28. Oktober geschrieben. Das ist natürlich nicht richtig gegenüber Brief 35 , der den Vermerk 17. Oktober trägt. Nach dem vorhergehenden Briefe st 35 nicht sogleich geschrieben, wie S. 26 I zeigt:

\section{Si me tins assez longuement, Que n'avoie pas l'aisement \\ D'envoyer vers sa douce face.}

Ebenso steht in dem Briefe selbst: se je n'ay envoie par devers vous si tost come je deüsse, si le me vueilliez pardonner. Diese Bemerkungen würden überflüssig sein, wenn er binnen acht Tagen einen Brief schreibt, einen von ihr erhält und darauf wieder antwortet. Indessen muls der Brief im Oktober geschrieben sein, da in ihm steht: Je pense a estre a ceste Toussaint a Saint Quentin, d. h. am 1. November. Dieser ist also später. Nun kommt Brief 36 , der wieder wie 34 das Datum des 28. Oktobers trägt; hier wird ausdrücklich gesagt: Escript le jour Saint Symon et Saint Jude vingthuitiesme jour d'octembre. Bemerkenswert ist, dafs der briefliche Verkehr ein sehr reger ist, da in einem Monat sechs Briefe gewechselt sind; das ist auch im November der Fall, wo man die Daten indes sofort als unrichtig erkennt. Ueber die Zwischenzeit bis zu Brief 37 ist nichts gesagt. Geschrieben ist dieser am 3. November. Die Dame antwortet an demselben Tage, wo sie den Brief erhält, S. 278:

Apres ceste lettre presente Ne fist une moult longue attente Ma dame bonne et belle et sage; Ainsois delivra mon message Si brief, que ce fu la journee Que ma leltre lui fu donne. 
Der Brief 38 ist verfalst am 5. November. Sie hat den seinigen demnach nach zwei Tagen erhalten. S. 279 schreibt sie, sie würde, um eine Zusammenkunft $\mathrm{zu}$ ermöglichen, in acht Tagen an dem ihm bekannten Orte sein. $\mathrm{Da}$ solle er sobald als möglich gute Nachrichten hören. S. 280 heilst es weiter:
Longuement pas ne demoura
Que ma dame son demour a
Mue en un autre manoir.
Et si vous jur, qu'elle m'escript.

Nach genau acht Tagen, am I3. November, schreibt sie von jenem Orte aus an ihn (Br. 39), dafs er zu ihr kommen und seinen Sekretär mitbringen möge. Machaut schickt nach seinem Sekretär, der drei Tagereisen entfernt ist, wohl sofort; dieser kommt auch sogleich, S. 283:
Si n'arresta jour ne demy
Jusqu'atant qu'a moy fust venus.
Car il desiroit plus que nuls
$A$ savoir que je li vouloie,
Qui en tel haste le mandoie.

Nun schreibt Machaut weiter:

Ce fu droit ou mois de novembre

Vingt-huitieme jours, bien m'en remembre.

Die Zeit ist danach schon etwas lang, wenn der Sekretär und sein Herr so grofse Eile haben.

Nun erfährt der Dichter von dem Verhalten der Dame, infolge dessen beschliefst er nicht zu ihr zu reisen. Die nächsten Angaben über die Zeit stimmen nun gar nicht zusammen. Man ersieht hier nicht, ob die Erzählung in der richtigen Zeitfolge weiter geht oder ob Episoden der spätern Zeit voraufgenommen sind. Ist ersteres der Fall, so sind die Angaben unter sich in Widerspruch; sowie wir aber letzteres annehmen, stehen sie nicht im Einklang mit den spätern Briefen und den Handlungen Machauts. Er hat also beschlossen, die Dame zu meiden.

\section{S. 306: Aprés des jours plus de quarante \\ Ou environ, que je ne mente,}

nach 40 Tagen also, teilt ein Bekannter mit, dals sie einen andern Liebhaber habe, der seine Sache besser vertrete. Soll das nur beiläufig bemerkt sein? Wenn nicht, so kommen wir vom 28. November an in den Anfang Januar 1364. Auf derselben Seite sagt er weiter:

\section{Aprés environ trois sepmaines \\ Chevauchai par mons et plaines \\ Pour viseter un mien seigneur.}

Allerdings könnte man das ja vom vorigen Punkte, Ende November, an rechnen. Dann wäre er im Dezember zum Dauphin geritten. 
Bessier muls es aber zum unmittelbar Vorhergehenden kommen; wir bekommen dann den Anfang des Februar 1364. Beides sind indessen keine geeigneten Monate zu grölseren Reisen par mons et plaines, besonders für einen Herrn von des Dichters Gesundheit und Körperbau. Es wird nun erzählt, dafs er hier verspottet wird wegen seiner Liebe. $\mathrm{Er}$ fährt dann fort:

$S i$ vous diray ce que je fis,

Bien croy que ce fu mes profis.

Nun erzählt er, dafs er ihr Bild eingeschlossen hat. Er beginnt, S. 308:

\section{Ce fu droit en mois de novembre Qu'on fait feu en sale et en chambre, Si demouray en ma maison, Jusqu'a la nouvelle saison.}

Das ist doch mit dem Vorigen gar nicht übereinstimmend. Mindestens wäre nach den erwähnten drei Wochen Dezember. Vorher schliefst er das Bild nicht ein, ehe er die trüben Erfahrungen am Hofe macht. Aufserdem behauptet er, er sei bis zur neuen Jahreszeit, d. h. wohl zum Frühling, zu Hause geblieben, während er doch kurz vorher sagt, er sei durch Gebirge und Ebenen geritten. Danach ist doch anzunehmen, dals er den Gang der Ereignisse, wie sie aufeinander folgen, schildern will. Zusammenreimen lassen sich die obigen Angaben unmöglich. Dafs der Text verderbt ist und die Zeilen vielleicht in falscher Reihenfolge dastehen, ist kaum anzunehmen. Später werden wir versuchen, Umstellungen vorzunehmen, doch bekommen wir, wie gleich bemerkt sei, nichts $\mathrm{Zu}$ friedenstellendes. Soll man aber hier wieder eine Absicht des Dichters annehmen? Es handelt sich hier nicht um bestimmte Daten, auch nicht um notwendige Angaben, die man hätte unbedingt einfügen und, damit der Leser grölsere Schwierigkeiten habe, verändern müssen, sondern um unwesentliche Bestimmungen. Dem Dichter ist es darum zu thun, die Gröfse seines Leids und seiner Kränkung uns möglichst eindringlich und lebendig vorzutragen. Dabei achtet er nicht auf diese zufäligen Zeitangaben, sondern schreibt solche hin, wie sie ihm in den Sinn kommen.

Auf S. 309 nun, nachdem er seine Trauer ausgedrückt hat und all das Obige vorausgegangen ist, fährt er fort:

\section{Ne demoura pas longuement, Qu'uns messages soudeinnement \\ Vint a moi ...}

Die erste Zeile hat hier gar keinen Sinn. Er hat die oft gebrauchte Anknüpfungsphrase an dieser Stelle zur Unzeit angewandt. Denn vorher sagt er doch, dals er lange zu Hause sitzt. Es auf die Komposition der Ballade S. $309 \mathrm{zu}$ beziehen, hätte gar keinen Zweck und liegt auch nicht in der Absicht des Dichters. Der hier erwähnte Bote bringt von der Dame Brief 40. Dals das Datum, 
nach $A$ und $C$ der 13., nach $B$ der 12. November, wieder falsch ist, bedarf keines Beweises, zumal auch in Brief $4 \mathrm{I}$ zum dritten Male dieses Datum wiederkehrt. Die Dame schreibt, dafs sie seit der Lichtmesse, la Chandeleur, d. h. dem 2. Februar, keine Nachricht von ihm hat. Diese Angabe stimmt natürlich mit dem Datum auch nicht überein. Aufserdem ist gar nicht ersichtlich, wie sie Anfang Februar Nachricht von ihm bekommen soll, da er doch Ende November den Verkehr abgebrochen hat. Sie sagt da auch: et si, vous ay depuis escript et daireinnement par vostre secretaire, eine merkwürdige Stelle, auf die wir noch zurückkommen. Wenn Machaut dem Wunsche der Dame Folge leistet, dafs er par ce message schreiben soll, so mufs er wohl bald antworten. Wie schon erwähnt, hat auch dieser Brief $4 \mathrm{I}$ als Datum den I3. November. Im Inhalt berührt er das Vorgefallene nicht. Auf S. 314 in Brief $4 \mathrm{I}$ sagt der Dichter, er werde zu ihr kommen la saint Andrieu passé ou plus tost se je puis. St. Andreas ist der 30. November. Die Dame sagt also, seit Anfang Februar habe sie nichts von ihm gehört, er antwortet flugs, Ende November will er kommen! - Er sagt, von den unangenehmen Ereignissen habe er ihr nichts mitgeteilt, um ihr keinen Kummer zu bereiten, auch weil dazu später immer noch Zeit war, S. 315:

\section{et messages trop demourer \\ Ne puet, ne tart hurter a porte, \\ Qui maises nouvelles apporte.}

Unangenehme Nachrichten kann man nie spät genug mitteilen. Machaut fährt dann fort:

\section{Presque toute la semaine M'endormi a moult grant peine.}

S. 315. Plus plouré avoie et gemy

Cent fois que n'avoie dormy.

Ist er jetzt „die ganze Woche“ wieder besonders traurig, oder ist das sein gewöhnlicher Zustand seit zwei bis drei Monaten, oder wird jetzt wieder die Zwischenzeit vergessen und nun angegeben, dafs die ganze traurige Sache vor einer Woche sich abgespielt und er da das Bild eingepackt hat, da nun wieder von diesem die Rede ist und er es endlich hervorholt? Diese Fragen kann man kaum entscheiden, und obige Bemerkung ist unklar.

Der Dichter erzählt jetzt eine Menge Sachen, die nicht hierher gehören, füllt damit einen grofsen Raum aus. Wieviel Zeit vergeht, ist nicht angegeben, S. 341 :

Toutevoie finablement

Je m'avisay que nullement

En ce point vivre ne povoie;

Que tousdis merencolioie...

Infolge dessen schreibt er Brief 42 , datiert vom I6. Juni. Hierin steht, er habe seit Ostern nichts an ihrem Buche gethan. Im all- 
gemeinen kann das Datum dieses Briefes richtig sein. In demselbren erzählt er, was er von ihr vernommen hat. Die Dame wird darüber ganz traurig und erschreckt, dichtet eine Ballade, deren dritte Strophe sie vor Schmerz nicht vollenden kann, und legt diese dem folgenden Briefe 43 bei. Danach sollte man meinen, sie habe den Brief bald geschrieben. Indes ist das Datum der 10. Oktober. Die Dame klagt auch, dafs sie sehr lange Zeit keine Nachricht von ihm hat. Er habe sie doch besuchen wollen, die Wege seien besser als je seit Ostern. Danach wird hier nicht auf Brief $\mathbf{4 2}$ Rücksicht genommen, weiterhin geschieht es aber. P. Paris bemerkt erst in der Fulsnote: Nous sommes au 10. octobre 1362, verbessert das aber in den Anmerkungen S. 405 in 1363 . Doch ist auch das noch nicht richtig. Nach den verschiedenen Daten und Zeitbestimmungen mufs es bereits 1364 sein, zumal auf Brief 33, der gerade ein Jahr vorher geschrieben sein soll - geschrieben ist dieser am 9. Oktober 1363 - Bezug genommen wird.

Nachdem Machaut den Brief erhalten hat, fährt er fort, S. 348:

Si ne demoura pas quinseinne

Qu'en un lundi, a bon estreinne

Un mien amy qui estoit prestres

Vint a moy.

Diesem hat die Dame gebeichtet und die Erlaubnis gegeben, die Beichte Machaut mitzuteilen. Dazu hat er einen Beglaubigungsbrief (44) mit dem Datum 8. März. Man bedenke, seit dem andern Brief vom Oktober sind vierzehn Tage vergangen. Und doch soll der Brief im März geschrieben sein. Die Rechnung ist eigentümlich. Den Antwortbrief (45) für die Dame, der vom 10. April datiert ist, giebt Machaut dem Priester mit. Die Zwischenzeit zwischen 44 und 45 erscheint $z u$ lang; es ist nicht angegeben, dafs der Priester anderswo gewesen ist, dafs er sich lange beim Dichter aufhält, oder Aehnliches. Mit diesem am 10. April geschriebenen Briefe macht er sich direkt zur Dame auf, S. 366:

$A$ tant se departi de moy,

Le premier jour du moy de Moy.

Das stimmt wieder nicht. Vor Ostern ist der Brief allerdings geschrieben. Denn S. 36I steht environ ceste Pasque je metteray tel peine a acomplir. - Der letzte Brief der Dame (46) ist ohne Datum, er wird an das Vorhergehende angeschlossen mit den Worten:

Vesci la lettre qui tesmongne

L'effect de toute la besongne

Que mon cuer et ma dame chiere

M'escript a bonne et lie chiere,

Et qui a la mienne respont,

Qui bien l'entent en bien l'espont.

In dem Briefe selbst sind keine Zeitangaben gemacht. Die Daten der letzten Briefe müssen sich auf das Jahr 1365 beziehen. 


\section{Die Daten der Briefe.}

Die Hauptschwierigkeit bei der Untersuchung und Vergleichung der Zeitangaben machen die Daten der Briefe. Wir wollen nun versuchen, die sich widersprechenden Daten der einzelnen Briefe in Einklang $\mathrm{zu}$ bringen. Das ist entweder möglich durch Umstellung einzelner und Einordnung nach den Daten oder durch Umänderung der Daten, soweit das nicht mit der Erzählung in Widerspruch kommt. Fragen wir zunächst, wie diese offenbaren Irrtümer in das Buch hineinkommen konnten, und fassen wir die möglichen Fälle einzeln ins Auge.

Der Irtum liegt entweder beim Dichter selbst oder beim Schreiber oder die Ueberlieferung ist mangelhaft. Er kann beabsichtigt oder unbeabsichtigt sein. Die Möglichkeit, die Schuld auf Ueberlieferung oder den Schreiber zu schieben, kann folgende Fälle ergeben:

I. Es können einzelne Partieen schlecht und undeutlich geschrieben gewesen sein, spätere Abschreiber haben das Richtige nicht herausgefunden und Konjekturen gemacht.

2. Einzelne Teile sind durcheinander geraten, derart, dafs das Werk zuerst in einzelnen Heften abgefa/st, dann zusammengeschrieben wurde und dabei Teile an falsche Stellen gekommen sind. Dabei ist $z \mathfrak{u}$ beachten, dals der (erste) Schreiber vielleicht manches falsch gestellt hat und dann durch Verweisungszeichen in der Handschrift anders ordnen wollte.

3. Die Briefe sind später in den Text eingefügt in Lücken, die zu diesem $Z$ weck freigelassen waren, und dabei an falsche Stellen gekommen.

4. Der Schreiber hat absichtlich Fälschungen vorgenommen.

Eine andere Möglichkeit wäre, dem Dichter die Schuld zuzuschieben. Hier kann dann nachlässige Verwechslung beim Eintragen der Briefe oder absichtlich falsche Angabe der Daten angenommen werden.

Bei vorliegendem Werke kann aber von schlechter Ueberlieferung nicht gesprochen werden; denn es liegt in drei sehr gut erhaltenen, schön und sorgfältig geschriebenen Handschriften vor, die aus des Dichters Zeit herrühren, vielleicht vom Dichter selbst durchgesehen wurden. Bei Hs. B kann man das wohl sicher annehmen, da diese ein Prachtband ist, der zum Geschenk für den Herzog von Berry bestimmt war. Ja, Tarbé nimmt an, dafs diese des Dichters eigene Handschrift zeige, da die Briefe von einer andern Hand in den Text eingetragen sind. Auch die andern Handschriften sind sorgfältig ausgeführt, von Verweisungszeichen ist nichts zu sehen. Es könnten die Briefe nur an falsche Stellen eingetragen sein. Bei den ersten sechs ist das auch der Fall. Nach P. Paris' Ansicht sind sie von Machauts Sekretär falsch gestellt (Pr. IX). Die von ihm angenommene Reihenfolge dürfte die richtige sein. Die übrigen Briefe hat er in der vorgefundenen 
Reihenfolge gelassen. Es handelte sich hier also nur um Briefe ohne Daten. Betreffs der Briefe mit zum Teil kaum annehmbaren Daten geht seine Ansicht nun dahin, dafs Machaut die Angaben absichtlich falsch gemacht habe, damit die Nachforschung über das geschilderte Verhältnis erschwert werde, und zwar habe er das auf Wunsch seiner Freundin gethan. Es wäre das ja eine ganz annehmbare Erklärung, wenn man sähe, dafs der Dichter mit seinen Aenderungen wirklich etwas erreicht habe. Doch ist dies durchaus nicht ersichtlich. Und wenn diese Annahme auch bei den Daten zuträfe, so doch nicht bei den Zeitangaben im Text. Man mufs natürlich nicht den heutigen Standpunkt dabei einnehmen, dals wir überhaupt von der Sache nichts wissen, sondern Rücksicht darauf nehmen, dafs die Veröffentlichung des Werkes natürlich zu vielen Fragen und Nachforschungen seitens der Zeitgenossen über die Natur des Liebesverhältnisses und die Hauptpersonen Anlals gab. Indes würde auch hier eine Aenderung der Daten zu nichts führen, da sie für diejenigen, welche die Beziehungen beider kannten und das sind nach des Dichters Angaben nicht wenige - überflüssig sind und keine Geheimnisse verraten, den andern aber, die die in Frage kommende Dame nicht kennen, durch die richtigen Daten allein kaum ein Mittel gegeben ist, sie ausfindig zu machen. $\mathrm{Zu}$ dem würden für diesen Zweck die Aenderungen wohl in solcher Weise vorgenommen sein, dafs man nicht sofort das Widersprechende bemerkt, nicht sofort die Absicht zu täuschen erkennt, sondern in einer Art, die den Schein des Wahren hätte und die Nachforschungen auf falsche Spuren leitete.

Nehmen wir den andern Fall an, Eintragung an falschen Stellen, so ergiebt sich Folgendes. Eine Umstellung der Briefe in der von den Daten geforderten Reihenfolge ist unmöglich, da dadurch offenbare Widersprüche neu hineinkämen. Der Text der Erzählung, wie er vorliegt, leidet keine Aenderungen. Solche wären aber unbedingt nötig, wollte man die Briefe in andrer Weise ordnen. In Betracht kämen hier $\mathrm{Br} .32,34,35,36 . \mathrm{Br} .32$ trägt das Datum des 5. Mai und steht $z$ wischen September und Oktober, er mülste dann nach $4 \mathrm{I}$ kommen. Br. 34 und 35 mü/sten umgestellt werden. Die übrigen $(42-46)$ zu ändern, geht auch nicht, da sie offenbar aus verschiedenen Jahren sind.

Wir können also in dieser Weise keine Umstellungen vornehmen, sondern müssen prüfen, ob die Reihentolge dem Sinne nach die richtige ist, und wenn, wie dann die hieraus sich als falsch erweisenden Daten am wahrscheinlichsten abzuändern sind. Wir müssen also die Reihenfolge nach dem Sinne, im Zusammenhang mit der Handlung und in Vergleichung mit den andern Briefen feststellen und etwa hieraus sich nötig machende Umstellungen vornehmen. Können wir dadurch ein klares Bild des Geschichtsganges gewinnen, so ist eine Abänderung der Daten vorzunehmen. Die Erklärung der falschen Zahlen steht allerdings dann noch dahin. Gelingt es aber nicht, die Zeitangaben nach 
richtiger Textstellung in Einklang $\mathrm{zu}$ bringen, so ist auch eine Aenderung der Daten zwecklos.

Für diese Untersuchung kommen nicht in Betracht die Briefe I-26, da sie keine Daten haben. Ihre Stellung giebt auch, was den Inhalt anbetrifft, zu keinem Bedenken Anlars, nachdem 1-6 richtig gestellt sind. Von Wichtigkeit sind höchstens 19-26; die andern sind vor Machauts Rückreise nach Reims geschrieben. Wir haben also zu untersuchen, ob die Briefe immer im Zusammenhang stehen, d. h. wodurch der folgende jedesmal mit dem vorhergehenden verbunden ist und worauf er Bezug nimmt. Man mufs also den Faden finden, der den einen Brief immer mit dem andern verknüpft. Geht der Zusammenhang verloren, so ist unter Umständen eine Umstellung vorzunehmen, wo nicht, so ist die Umstellung ausgeschlossen. Ich gebe hier stets eine Hauptstelle, die gerade für den Ort des betreffenden Briefes wichtig ist.

Brief ig nimmt Bezug auf Machauts Abreise (das Wunder der Göttin). 20 desgleichen. 21 Schilderung der Heimreise des Dichters, Zusammentreffen mit Esperance. 22 Freude über seine glückliche Heimkehr, der Lay d'Esperance gefällt der Dame sehr.

23 ist ohne Bezug auf 22, in Form eines Klagelieds. 24 bezieht sich aber darauf.

In 25 entschuldigt sich M. ${ }^{1}$ betreffs 23 , es thut ihm leid, dals sie dadurch, wie in 24 steht, gekränkt ist. Mitteilung, dafs verschiedene Herren von ihrem Briefwechsel wissen.

In 26 freut sich die D. über das Bekanntwerden ihrer Liebe; sie bedauert, dafs sie das Verhältnis nicht eher angeknüpft hat.

Von jetzt an wird auf Bitten M.s immer das Datum hinzugefügt, da sonst die Briefe schwer zu ordnen seien. Br. 27 nimmt Bezug auf die Stelle in 26, dafs sie ihre Liebe nicht früher begonnen haben. M. bittet die D., mit ihrer Schwester nach Reims zu kommen. Geschrieben 8. August.

28. Die D. bittet M., um Mitte August an einen bestimmten Ort zu kommen. In 27 ist gesagt, M. wache die Nächte bei seiner Arbeit; sie sagt nun, sie thue das auch in Gedanken an ihn. Geschr. Sonntag vor Mitte August. Er soll nicht eher schreiben als bis sie ihm wieder Nachricht giebt.

29. Sie hat lange nicht geschrieben. Seit 20. August ist sie an dem bekannten Orte. Gegen den 7. September hat sie einen Traum gehabt, den sie erzählt. Geschr. 17. Sept.

30 und 3 I gehören zusammen, 30 ist nicht selbständig. In 31 wird der Traum erwähnt. Frage, warum sie solange nicht geschrieben hat. Laiette erwähnt. Ohne Datum.

32. Erwähnung der laiette. Frage von 3 I beantwortet. Complainte wegen des Inhalts vom 30 . Sie wünscht das Gedicht L'ueil qui est le droit archier bald zu haben. Geschr. 5. Mai.

1 Ich nehme der Kürze halber wieder für den Dichter die Bezeichnung M., für die Dame $D$. 
33. Fr will L'ueil qui est mit Noten senden, entschuldigt sich wegen $\mathrm{Br}$. 30. Er sagt, er sei nicht würdig, sie zu lieben.

34. Die D. nimmt seine Entschuldigung an. Darin dafs er glaubre, ihrer nicht würdig zu sein, habe er ganz Unrecht. Bittet um Zusendung des Buches durch denselben Boten. Geschr. 28. Okt.

35. M. schickt das gewünschte Buch. Hier und in 33 wird die Anwesenheit des Herzogs von Bar in M.s Hause erwähnt. M. will am I. Nov. nach St. Quentin reisen, Geschr. 17. Okt.

36. Sie hat das Buch erhalten. Wenn er nach St. Quentin gehe, solle er ihrem Bruder Nachrichten für sie geben. Geschr. 28. Okt.

37. Er ist nicht nach St. Quentin gegangen. Geschr. 3. Nov.

38. Sie freut sich, dafs er nicht nach St. Quentin gegangen ist. In acht Tagen will sie an einem Ort sein, wo sie sich treffen wollen. Geschr. 5. Nov.

39. Sie ist an den betreffenden Ort gekommen. Er soll dahin reisen. Sie giebt Weisungen, wie er sich verhalten soll. Geschr. I3. Nov.

Hierauf wird der Bruch M.s mit der Dame infolge der Erzählung des vornehmen Freundes mitgeteilt. Es tritt eine grofse Pause ein in dem brieflichen Verkehr.

Es folgt Brief 40, das Datum ist wie in 39, der 13 . Nov. Dem Inhalt nach ist dieser Brief nach dem Bruch anzusetzen, da die Dame hierin wieder anzuknüpfen sucht. Dafs der 13. Nov. falsch ist, ergiebt der Brief selbst, worin sie sagt, sie habe seit Februar keine Nachricht von ihm. Nach der Darstellung des Gedichts fühlt sich M. veranlarst, an das Fräulein zu schreiben, aber nichts von dem Verdacht mitzuteilen. Br. 41 enthält davon allerdings auch nichts. Er bezieht sich unmittelbar auf 39 , doch so, dafs wir trotz des Dichters Angabe ihn auf keinen Fall hinter 40 lassen können. Denn der Inhalt und ganze Sinn des Br. 4 I geht unmittelbar auf 39 und lälst erkennen, dafs er wohl gleich dem Ueberbringer von 39 mitgegeben wurde, noch ehe M. etwas von dem Gerede erfahren hatte. Es wäre doch sinnlos, in der Weise, wie es hier nach der jetzigen Stellung geschieht, $40 \mathrm{zu}$ ignorieren und $39 \mathrm{zu}$ beantworten. Er sagt: jai mandé mon secretaire. Ich verstehe das so, dals er diesen, der drei Tagereisen entfernt war, zu sich entboten hat, dafs dieser aber noch nicht da war. Von einer gedrückten Gemütsstimmung ist auch gar nichts zu merken. Vom psychologischen Standpunkte aus ist die Stellung und Absendung von 4 I unmittelbar nach 39 die einzig gerechtfertigte, obwohl an den Handschriften äufserlich nicht $\mathrm{zu}$ bemerken ist, dafs etwas falsch stünde. Es fragt sich dann aber, wie der Text dazı pafst. Nach diesem mülste für 4 I freilich ein anderer Brief eingesetzt werden. Ueberhaupt sind, wie oben gezeigt, die Zeitangaben hier ganz in Widerspruch. Der Zeit nach mülsten die hier geschilderten Vorgänge, um auch nur einigermalsen Ordnung zu schaffen, sich folgendermalsen abspielen. 
Nach V. 7569 wäre anzuschliefsen V. $7616-7664$, dann käme $7570-7615$, dann 7665 und Brief 40. Man könnte sich das so denken, dafs der Dichter infolge der Erzählung des Freundes den Winter über zu Hause bleibt und ihr Bild einschliefst. Später hört er hier, nach sieben Wochen, dafs sie einen andern Liebhaber hat. Frühzeitig noch im Frühling reitet er zu seinem Herrn. Mit traurigem Gemüt reitet er heim, so dals er die ganze Woche nicht schlafen kann. Dann kommt der Bote von der Dame mit Brief 40. Doch können wir diese Aenderungen, welche den Text in Bezug auf die Zeitbestimmungen in Einklang bringen würden, nicht vornehmen, ohne die verbindenden Verse vor Brief $4 \mathrm{I} \mathrm{zu}$ streichen, und diesen Gewaltstreich darf man sich doch wohl nicht gestatten. Denn nach 39 kann man diese Verse auch nicht setzen. Die Widersprüche lassen sich hier auch durch Umstellung nicht völlig beseitigen. Die Dame hat in Br. 40 so grofse Sehnsuchl nach M. gezeigt, dafs es auffallen mülste, wenn sie auf Brief $4 \mathrm{I}$, sei es wie er hier steht, oder auf einen neu eingefügten, nicht geantwortet hätte. Zwischen Brief 40 und 42 liegt ein langer Zwischenraum. M. will zuerst gar nicht antworten, bis er es nicht länger ertragen kann (S. 34I) und an sie schreibt, was ihm erzählt worden ist, Brief 42. Dafs sie lange keine Nachricht von ihm bekommen hat, sagt sie selbst in Brief 43 . In 42 ist entgegen der sonstigen Gewohnheit nichts von Beantwortung eines früheren, Dank für denselben u. s.w., gesagt. Er steht also allein. Seine Stellung ist der Erzählung entsprechend. Brief 43 der Dame schlielst daran an: er soll dem Gerede nicht glauben. Dieser Brief ist sicher nach 40 geschrieben, da darauf Bezug genommen wird auf S. 345, Z. 2-7 und I I-I 2 von unten. In 43 wird das Gedicht En lieu de bleu dame vous vestes vert erwähnt, das er in seinem Schmerz gedichtet hat. Dieses Gedicht giebt Veranlassung, den Priester an M. zu senden, der ihm ihre Beichte mitteilen soll. Brief 44 ist der Beglaubigungsbrief, steht richtig. 45 bezieht sich auf die vernommene Beichte, der livre du Voir Dit ist ziemlich beendet. Es wird von joiaus gesprochen, deren Sendung M. entschieden milsbilligt. M. versichert, dals Frieden und Freundschaft fortan zwischen ihnen herrschen sollen. In Brief 46 werden die joiaus wieder erwähnt; dieser Brief bildet den Abschlufs, die Dame giebt ihm ebenfalls die Versicherung dauernder Freundschaft.

Die Untersuchung hat uns gezeigt, dafs an der Reihenfolge der Briefe nichts $\mathrm{zu}$ ändern ist, aufser dafs 40 und $4 \mathrm{I}$ umzustellen wären. Ihr innerer Zusammenhang dürfte so ziemlich erwiesen sein. Es handelt sich also zunächst weiter darum, nachdem die Reihenfolge dem Sinn entsprechend festgestellt ist, die richtigen Daten $z u$ finden, bezw. die vorhandenen zu verändern. $O b$ dann ein klares Bild gewonnen wird, muls sich hieraus ergeben. $\mathrm{Zu}$ behandeln sind insbesondere noch die verschiedenen dunklen Angaben der letzten Briefe, zugleich auch die Frage, ob wir an- 
nehmen müssen, dafs einige Briefe mit oder ohne Absicht des Dichters nicht mitgeteilt sind.

Wir haben nun nochmals also die Briefe von 27 an in Bezug auf die Daten zu betrachten. Vergl. dabei die Bemerkungen über die Zeitangaben im allgemeinen.

Brief 27, der erste mit Datum, ist vom 8. August. Das kann richtig sein. Ebenso ist $\mathrm{Br}$. 28, Sonntag vor Mitte August, richtig.

Br. 29 ist datiert vom 17. Sept., nach Hs. C vom 27. Sept. Dieses Datum wie die von 30-33 stimmen mit den Textangaben nicht überein. Denn zweimal ist ausdrücklich erwähnt, dals M. über zwei Monate keine Nachricht von der Dame erhielt.

\section{S. 212 Et ce fu deux mois tous entiers \\ Et aveuc ce j'entrai en tiers.}

Eine Aenderung ist hier nicht möglich, etwa aus der II. der Handschrift eine .I. zu machen, da das tiers durch den Reim belegt ist. Aufserdem steht auch S. 22 I il ha pres de neuf semaines. Das Datum des Briefes aber so $\mathbf{z u}$ bestimmen, dafs B. 29 erst nach Mitte Oktober, was hiernach das Richtige sein würde, zu datieren wäre, ist wegen sämtlicher späteren Angaben unmöglich. Es bleibt hier ein Widerspruch, der sich nicht beseitigen läfst. Abgesehen von der historischen Echtheit, könnte S. 2 I 2 als unbewufste Erinnerung an S. 24 vom Dichter geschrieben sein:

212 (a) Et ce fu deux mois tous entiers.

24 (b) Car ja fu deux' mois tous entiers.

Weiter a

ains ala en autre contree

Et au lieu je ne cognoissoie creature.

b pour ce qu'elle estoit alee demourer en autre contree. - Car personne ne cognoissoie en lieu.

Auch sonst haben beide Stellen in der Anlage grofse Aehnlickeit. Man ist versucht, an eine Einwirkung von S. 24 auf die Komposition von $212 \mathrm{zu}$ glauben. Eine Aenderung mit Brief 27 und 28 vorzunehmen ist nicht angängig, wir kämen mit diesen Briefen sonst in die erste Julihälfte, was wegen $\mathrm{Br}$. 20-26 unbedingt falsch ist.

In Brief 29 liegen also zwei verschiedene Daten vor, der 17. und 27. P. Paris hat sich für das erstere entschieden. Hierbei müssen wir die Angaben in dem Brief selbst verwenden. Die Dame schreibt, seit 20. Aug. (A und B) sei sie in X. Nach 17 Tagen (Hs. B hat , 16 Tage') reist sie mit ihrer Schwester zum Bruder in der Brie. Da ist sie 15 Tage, bis sie an den Ort reist, von wo sie schreibt. 20. Aug. $+17+15$ ergiebt den 21. September. Das würde schon über das Datum des 17 . hinausgehen. Hs. C hat aber statt 20. August den 10. Dann kommen wir zum I I. Sept. + Reise. Danach könnte 17. richtig sein. Doch möchte ich den IO. als nicht richtig annehmen in Ansehung von Brief 28. Dieser ist, wie erwähnt, am Sonntag vor Mitte August geschrieben. Das wäre 
frühestens der 9. (wenn erst am darauffolgenden Sonnabend der 15. wäre). Die Dame schreibt, sie würden ce lundi prochain venant abreisen. Ich glaube, dafs damit eher der 18 . als der 10. gemeint ist, da sie auch in den Oktaven von mi-aoust dort sein wollen. Wenn sie am 10. abreisen, so würde bei der Rechnung für die Reise dann keine Zeit bleiben; denn sie sind anscheinend noch in Paris, so dafs sie nicht am selbigen Tage nach X. kommen können. Ich möchte also als Datum von Brief 29 den 27. Sept. setzen, ebenso aber den 20. August beibehalten gegenüber dem IO. Der 27. palst auch zu der Angabe Je delivrai son messagier le lendemain und zu der, dafs M. den Brief an der vigile St. Michiel, dem 28. Sept., erhalten hat.

Brief 30 ist nicht abgesandt worden, er war in der Zwischenzeit vor 29 geschrieben und 31 beigelegt. In 31 ist kein Datum angegeben. Doch wird er bald geschrieben sein, S. 240: Vostre frere vint a moy le jour St. Michiel au matin. Danach ist er am 29. September wohl nicht geschrieben, der Ausdrucksweise halber, doch bald darauf. Merkwürdig ist, dafs das Datum fehlt, nachdem M. selbst kurz vorher die jedesmalige Hinzufügung gewünscht hat.

Brief 32 ist datiert vom 5. Mai. Dafs der Monatsname falsch ist, sieht man sofort; die Stellung des Briefes ist aber richtig. Wir müssen uns fragen, wie dieser ganz unpassende Monatsname hierherkommt. Mit Absicht ist das jedenfalls nicht geschehen. Ich glaube, der Sekretär oder der betreffende, der die Briefe mechanisch, ohne zu denken, abschrieb, konnte den Monatsnamen nicht lesen. Warum er nun gerade may setzt, ist nicht klar. Oktober war vielleicht abgekürzt und dazu undeutlich, so entsprach vielleicht die Länge des mit Ziffern VIII e geschriebenen Monatsnamens den Buchstaben may. Uebrigens sind in den Handschriften die Monatsnamen stets ganz ausgeschrieben.

Dafs das Datum von 33, der 9. Oktober, richtig ist, könnte man aus folgender Erwägung schliefsen, vorausgesetzt allerdings, dafs das Datum von 43 richtig ist. In diesem Briefe, datiert vom 10. Oktober 1364 , steht nämlich: Einsi me promistes vous, il a un an tout droit en ce mois, quant j'estoie au Biau chastel, que jamais ne m'escririez que je ne fusse vostre bonne et leal amie, ne diriez chose dont je me deusse courrecier.

In Brief 33 sind die betreffenden Stellen: ne vueilliez penser nullement que je vous tiengne pour bonne et pour leal. Et je vous promet et jur loyaument que se jamais vous ne m'escrisiez ne n'envoiez vers moy, ne se jamais je ne vous veoie, jamais je ne vous escriray, diray ne commanderay chose dont vous doiez courrecier a mon povoir.

Indessen ist das nur eine relative Bestimmung. Hs. A zeigt .ix. decembre; das ist natürlich falsch, denn auch hier sind dann die Oktoberdaten vorhanden. P. Paris glaubt, für 9. Okt. den 19 . setzen zu sollen, da der im Briefe erwähnte duc de Bar, wie M. schreibt, qui a geu en ma maison, mit dem Könige noch am 18. in Reims ist. Nach der Angabe a geu wäre er abgereist. Wie er 
aber damit die Daten der nächsten Briefe in Einklang bringt, sagt er nicht. Er mülste doch dann auch das Datum von 35 ändern. Aus dem von P. Paris angeführten Grunde allein zu ändern, scheint mir deshalb nicht ratsam. Der Herzog könnte ebenso gut vor dem 9. abgereist und dann zurückgekehrt sein. Bei den beiden nächsten Daten möchte ich aber eine Aenderung vornehmen. Dafs das von 34 falsch ist, liegt auf der Hand. Dafür ist zu setzen der 18. Oktober, in 35 der 27. Dafs zwischen 34 und 35 einige Zeit liegt, zeigt S. 26r: Si me tins assez longuement. Beide sind aber sicher vor dem 28 . Oktober geschrieben, sie liegen, wie oben gezeigt, vor Brief 36 . Denn hier ist das Datum so ausdrücklich genannt, dafs man da kein Versehen oder falsche Schreibung annehmen kann: Escript le jour Saint Symon et Saint Jude, vingthuitiesme jour d'octembre. Dals die Briefe schnell nach einander geschrieben sind, ist möglich, da die Dame auch in der Champagne sich aufhält, also nicht weit von Reims. Vor dem I. November müssen diese Briefe sicher liegen, wegen der erwähnten Reise nach St. Quentin, ebenso wie 37 nach dem 1. November. Da er datiert ist vom 3. November, kann man das Datum wohl als richtig annehmen. Brief 38 ist sofort wieder geschrieben, wie ausdrücklich bemerkt wird, am 5. November. Auch gegen das Datum von 39, den 13. November, ist nichts einzuwenden.

Durch diese Aenderungen ist die Reihenfolge der Briefe wenigstens haltbar. Ungelöst bleibt immerhin die Frage betreffs der neun Wochen vor Brief 29.

Für die sechs letzten Briefe lassen sich jedoch wirklich annehmbare Vermutungen kaum aufstellen. Zum Teil lassen sich die Widersprüche gar nicht beseitigen, bei den andern können wir mit Bestimmtheit über die Richtigkeit der Daten überhaupt nichts aussagen. Brief $4 \mathrm{I}$ haben wir oben vor 40 gesetzt. Im November 1363 mülste er seinem ganzen Inhalte nach geschrieben sein; St. Andreas, der 30. Nov., liegt später. Wollte man das Datum, den 13 . Nov., beibehalten, so mürste $M$. am selben Tage, wo er 39 erhalten, wieder geschrieben und dem Boten die Antwort gleich mitgegeben haben. Doch möchte man einen spätern Tag annehmen, da er in dem Briefe schreibt, er habe schon seinen Sekretär zu sich entboten; dieser kommt in grölster Eile, am 28. November. Der Weg beträgt drei Tagereisen. So könnte man als wahrscheinliches Datum vielleicht den 23. November ansetzen.

Nach des Dichters Angabe ist der Briefwechsel den ganzen Winter unterbrochen. Es würde demnächst Brief 40 kommen, der zum dritten Male das Datum des I3. Novembers trägt. Wie das dahin gekommen, ob durch Verwechslung des betreffenden, der die Briefe eintrug und vielleicht 39 mit vorliegen hatte, oder auf welche andere Weise, darüber lärst sich nichts feststellen. Auffallend ist es sehr, dafs drei Briefe dasselbe Datum haben. Dem Inhalte nach mufs dieser Brief ins Frühjahr 1364 gesetzt werden und nach dem 2. Februar geschrieben sein. Darauf habe ich noch 
zurückzukommen. Brief 42 , von $M$. abgesandt, nachdem er diesen Zustand nicht länger ertragen kann, trägt den Vermerk: Escript le seizieme jour de juing. Nach Ostern, das am 24. März 1364 ist, ist er geschrieben, vergl. S. 342 Je ne fis riens en vostre live puis Pasques. Betreffs 43 kann man keine bestimmten Vermutungen aufstellen; dem gegenüber stimmt das Datum von 44 aber nicht; ebenso wenig pafst das von $45 \mathrm{zu} 43$. Bei diesen letzten Briefen läfst sich eine bestimmte Zahl nicht feststellen. Brief 44 ist vielleicht an sich richtig, im Verhältnis zu 43 ist es das Datum aber nicht. Der ganze Zeitraum ist auch aufserst ausgedehnt, über anderthalb Jahre vergehen zwischen Brief 40-46; die definitive Einigung und der Abschlufs des Zwistes gehen sehr langsam vor sich nach den Zeitangaben, ganz entgegen den Schilderungen über die Gemütsund Seelenzustände der beteiligten Personen. Man vergleiche hierüber die Bemerkungen am Schlufs des Kapitels „Zeitangaben im allgemeinen".

Wir haben so gesehen, dafs wir auch durch Aenderung von Daten nichts erreichen, dafs es oft unmöglich ist, solche vorzunehmen.

\section{Sind etwa Briefe verloren gegangen?}

Wir haben nun noch zu untersuchen, ob etwa ganze Briefe verloren gegangen oder absichtlich nicht eingetragen sind. Vielleicht wären gerade diese wesentlich für das Verständnis und gäben uns über manches Unklare Aufschlufs. Fassen wir daher die Stellen ins Auge, welche auf Briefe Bezug haben, die nicht in dem Buche stehen.

I. In Brief 7, S. 57 lautet der Anfang: J'ai receues vos lettres. Depuis que je eus ycelles receues, le quatrieme jour ensieuant, je receues ycelles de quoy vous m'avez escript, et aussi les chansons.

Die Dame hat also Brief 6 erhalten, nachher den früher abgesandten. Das wäre Brief 4 ; dieser ist aber schon in 5 beantwortet. Es müfste also hier auf einen Brief Bezug genommen sein, der nicht überliefert ist. Er hat aber von einem nicht beantworteten Briefe nichts geschrieben, wie zu schliefsen wäre aus der Stelle: de quoy vous m'avez escript. Demnach mülsten dieser Angabe nach gleich zwei Briefe fehlen, die man aber gar nicht vermissen würde, wäre nicht die Bemerkung in Brief 7 . Nimmt man aber an, es ist das eine vom Dichter selbst geschriebene Bemerkung, auf die er kein Gewicht gelegt hat, so kommt man über diese Schwierigkeit hinweg.

2. S. 59 spricht M. von dem Bilde qu'en sa lettre me promettoit. Er schildert den Eindruck, den Brief 7 und die Nachricht, dals er ihr Bild erhalten solle, auf ihn gemacht hat. Aber in dem vorhergehenden Briefe steht davon gar nichts, auch in Brief 5 ist das Versprechen nicht gemacht. Eine Umstellung wegen dieser einen Bemerkung würde uns wieder in andere Widersprüche bringen, so 
dafs man obige Angabe entweder auf das Fehlen eines Briefes, worin das gestanden hätte, oder wieder auf eine Unachtsamkeit des Dichters schieben muls.

3. In Brief 40 schreibt die Dame: je n'ö̈ novelles de vous depuis la Chandeleur. Et si, vous ay depuis escript et daireinnement par vostre secretaire; et si li dis pluseurs choses de bouche lesquelles il vous devoit dire.

Hierbei ist Verschiedenes auffällig. Das Verhältnis wird bekanntlich nach des Dichters Erzählung im November abgebrochen und ganz ausdrücklich hervorgehoben, dafs kein Brief in der ganzen Winterzeit jusqu'a la nouvelle saison geschrieben ist. Hier behauptet die Dame, am 2. Februar von ihm Nachrichten bekommen zu haben. Sie hat seitdem geschrieben. Dieser ausdrücklich erwähnte Brief ist nicht vorhanden. Der Sekretär mürste ihn nicht abgeliefert haben. Es wird ja auch nichts erwähnt, dafs er ihre Aufträge ausgerichtet habe. Man mufs hierbei fragen, was der Sekretär bei der Dame gewollt hat, und sich wundern, wenn er da nichts über seines Herrn veränderte Gesinnung mitgeteilt hätte. In Brief 45 wird allerdings erwähnt, dafs der Sekretär von der Dame Geschenke und Aufträge übermittelt; das ist aber ein Jahr später, und die Verhältnisse sind wieder andere geworden. Nach alledem erscheint es mir höchst unwahrscheinlich, dafs diese Angabe in Brief 40 auf Wahrheit beruhe.

4. In Brief 43 schreibt die Dame: vueilliez savoir que je n'ay point veu le vallet que vous m'avez escript que vous m'envoiastes en moi de may ne n'en ay ö̈ nulles nouvelles. Hier ist es ähnlich wie bei Brief 7. Man findet in keinem Briefe M.s eine Erwähnung dieses valet; sonach wäre der betreffende Brief nicht vorhanden; aufserdem wäre auch der verloren gegangen, den er im Mai abgesandt hätte. Was der valet aber im Mai mit einem Brief an die Dame sollte, ist gar nicht einzusehen; denn M. schreibt doch erst im Juni, nachdem er den bisherigen Zustand nicht mehr ertragen konnte. Wir mülsten denn annehmen, es sei das ein Antwortbrief auf 40 in der Art, wie er im livre angiebt, dafs er nämlich noch nichts von dem Gchörten mitteilt, sondern allgemeine Redensarten macht. Es scheint ja nach 40 , nachdem wir 41 vor diesen gestellt haben, allerdings ein Brief zu fehlen, der den Bemerkungen M.s und dem verbindenden Text entspräche. Dieser Widerspruch wäre ja dann beseitigt. Indes hat M. nach folgender Stelle, für die ich eine andere Beziehung nicht finden kann, Brief 40 nicht beantwortet, sondern thut das erst mit 45 zusammen, nämlich S. 360:

$$
\begin{aligned}
& \text { Elle m'a, long temps a, tramis } \\
& \text { Une lettre si que j'ay mis } \\
& \text { En ces presentes la response. }
\end{aligned}
$$

Dem Sinne nach kann 45 wohl auf 40 mit antworten. Ein Mangel in der Komposition bleibt immer bestehen, da die Einordnung von 4 I mit zugehörigem Text unterblieben ist. Nehmen wir eine Fiktion 
des Ganzen an, so ist auf die Angabe in 43 kein Gewicht zu legen; nur damit das Interesse wachgehalten und Abwechslung geschaffen wird, ist sie gemacht. M. schreibt nun, er wolle Brief 40 ignorieren, nimmt darum 39 wieder vor, als er 41 schreiben will, und verfalst einen diesem entsprechenden Brief, der nachher freilich mit dem Text nicht in Einklang steht.

5. In Brief 46 schreibt die $\mathrm{D}$. von unes autres lettres dont je ne fis onques response. Die betreffende Stelle, wo er sagt, sie schreibe plus obscurement, plus briefment et de pieur lettre, befindet sich aber in Brief 45, den sie eben beantwortet. Weiter findet man keine Erklärung für die Stelle: Ne je n'eus de vous nouvelles puisque je vous escris par vostre vallet daireinnement. Das könnte höchstens auf 43 gehen. Es sind das aber nur Wendungen, die M. beim Briefschreiben gerade in den Sinn kommen.

Wir sehen, dafs man aus diesen Stellen kaum auf das Vorhandensein nicht eingetragener Briefe schliefsen kann, die die Widersprüche beseitigten. Im Gegenteil werden wir gerade durch diese Stellen mehr und mehr dazu gedrängt, eine freie Erfindung des Dichters anzunehmen. Eine wirkliche Klarheit in das Ende der Erzählung zu bringen erscheint nach dem Geäufserten unmöglich, da es sich nicht um falsche Schreibungen und äufsere Versehen handelt, sondern das Widersprechende in der ganzen innern Anlage liegt. Der Versuch, durch Umstellung der Briefe oder Aenderung der Daten die sämtlichen zeitlichen Widersprüche zu beseitigen, ist demnach als gescheitert zu betrachten. $\mathrm{Da}$ /s der Dichter mit Absicht so unklar geschrieben und die wirklichen Thatsachen auf ganz zwecklose Art so entstellt habe, ist meiner Ansicht nach auch ausgeschlossen.

Es bleibt uns demnach die eine Erklärung, die Wahrheit der ganzen Erzählung als einer Geschichte, die wirklich so, wie sie vom Dichter geschildert ist, sich abgespielt hat, und die Echtheit des ganzen brieflichen Verkehrs zu verneinen, worauf uns ja schon sachliche Bedenken und Widersprüche und der Stil geführt haben. Dieses nun im Verein mit den unlösbaren Widersprüchen in den Zeitangaben, wo man zum Teil klar erkennt, dals ganz unbeabsichtigte Fehler vorliegen, zumal wenn man die wirklichen Osterdaten zum Vergleich heranzieht, auf die der Dichter keine Rücksicht genommen hat, das alles berechtigt zu der Annahme, dafs wir es hier mit einem erfundenen, nicht historischen Stoff $\mathbf{z u}$ thun haben, trotz der angeblichen Urkunden und Beweise von P. Paris. Denn wie Suchier gezeigt hat, ist der Name der Peronne d'Armentières nicht aus dem Anagramm herauszulesen, und dann helfen auch die Urkunden nichts. Vielleicht ist hier die geeignete Stelle, um das letzte Beweismittel, das P. Paris anführt, zu streifen, das Gedicht von E. Deschamps. Dieser erwähnt allerdings den Namen Peronne in Beziehung zu dem verstorbenen Machaut, vgl. Tarbé, Euvres inédites d'Eustache Deschamps, 1849, Bd. III, 260. Doch 
beweist das nichts für die Echtheit der Briefe. Deschamps könnte diesen Nimen gerade in Bezugnahme auf das Rondel im Livre du Voir Dit, das den Namen Peronne zeigt, gebraucht und damit Machauts dichterisches Ideal gemeint haben. Dafs ein solcher Name genannt wird, ist noch kein Beweis für die Echtheit der Briefe. Aufserdem scheint das Verhältnis, wie es am Schlufs des Voir Dit geschildert wird, nicht mehr derartig zu sein, dals nach zwölf Jahren auf Grund dieses Deschamps zu den Versen ein Recht gehabt hätte.

Infolge obiger Ausführungen bin ich geneigt, Le Livre du Voir Dit für eine freie Erfindung des Dichters zu halten. Die Briefe und die angeblich von der Dame verfarsten Gedichte sind von Machaut selbst. Dadurch wird nicht etwa der Wert der Dichtung herabgesetzt; es macht diese eigenartige, reizende Komposition im Gegenteil dem Dichter von Reims alle Ehre, wenn man den Plan des Ganzen betrachtet und von einzelnen kleinen Mängeln der Ausführung absieht. Man beachte auch, dals man an den Gedichten der Dame keine geringere Meisterschaft im Vergleich zu denen Machauts entdecken kann. Ein Dichtertalent dieser Art würde auch von Zeitgenossen sonst erwähnt sein und in eigenen Werken fortleben, nicht nur in gelegentlich in ein anderes Buch eingestreuten Blüten seine Spur hinterlassen. Betrachten wir dazu den Stil und die Ausdrucksweise der Briefe, so findet man eine überraschende Aehnlichkeit, fast völlige Gleichförmigkeit, nichts von verschiedener Individualität, von einem Unterschied, der zeigte, dafs die Hälfte der Briefe von einem gereiften Mann und grofsen Dichter, die andere von einem jungen Mädchen geschrieben sei. Dazu kommen noch die Unklarheiten in den Angaben über die Komposition sowohl als betreffs anderer Dinge, die oft das Gefühl hervorrufen, als habe dem Dichter etwas Reales nicht vorgeschwebt und als seien deshalb die Ausdrücke so schattenhaft und unklar.

Das Werk besteht aus zwei ungleichwertigen Teilen. Der Einschnitt ist nach des Dichters Rückkehr von Paris nach Reims zu setzen, S. 163 .

Der erste Teil ist von bedeutend höherem Werte als der zweite, er zeigt viel grölsere Gestaltungs- und Erfindungskraft als dieser. Es ist das darauf zurückgeführt worden, dafs das Verhältnis an Wärme verloren habe, dafs die Dame ihre Gesinnung dem alten Dichter gegenüber geändert habe und er nun nicht viel Schönes mehr zu berichten wisse. Man kann es aber auch anders erklären. In der ersten Hälfte nämlich war der Dichter von seinem Stoff voll eingenommen und führte ihn schaffensfreudig und in lebendiger Darstellung zu einem Höhepunkt. Dann erlahmte das Interesse, andere Arbeiten nahmen ihn vielleicht in Anspruch, er suchte nun mit Gewalt einen Abschlufs herbeizuführen. Damit nun die Erzählung nicht zu einem allzu plötzlichen Ende kam, auch der zweite Teil an Umfang dem ersten entsprach, wurden die vielen Erzählungen aus Ovid u. s. w. als Füllmaterial eingeschaltet. 
Sie lagen dem Dichter fertig vor und machten ihm wenig Mühe. Vielleicht hat ihn auch die Phantasie hier verlassen; denn noch eine Steigerung herbeizuführen oder in angemessener Weise die Sache fortzusetzen, war schwer. Hieraus erklären sich auch die vielen Widersprüche und Irrtümer, die im zweiten Teile im Verhältnis zum ersten bedeutend überwiegen. Der erste Teil ist sorgfältiger durchgearbeitet, Irrtümer sind nur bei genauer Untersuchung zu finden. Hier hat ihm die Arbeit Vergnügen gemacht. Nachher hat er ohne genaue Prüfung, ob das Folgende im Einklang mit dem Früheren steht, stückweise weiter gearbeitet und nur das $\mathrm{Zu}$ nächstliegende berücksichtigt. Er hat das Werk jedenfalls sehr schnell zum Abschlufs gebracht und offenbar dann, froh damit zu Ende zu sein, nicht nochmals durchgearbeitet.

GEORG HANF. 